\title{
Simulating Smoke Filling in Big Halls by Computational Fluid Dynamics
}

\author{
W. K. Chow, C. L. Chow, and S. S. Li \\ Research Centre for Fire Engineering, Department of Building Services Engineering, Area of Strength: Fire Safety Engineering, \\ The Hong Kong Polytechnic University, Kowloon, Hong Kong \\ Correspondence should be addressed to W. K. Chow, beelize@polyu.edu.hk
}

Received 15 November 2010; Accepted 18 January 2011

Academic Editor: Guan Yeoh

Copyright ( 92011 W. K. Chow et al. This is an open access article distributed under the Creative Commons Attribution License, which permits unrestricted use, distribution, and reproduction in any medium, provided the original work is properly cited.

Many tall halls of big space volume were built and, to be built in many construction projects in the Far East, particularly Mainland China, Hong Kong, and Taiwan. Smoke is identified to be the key hazard to handle. Consequently, smoke exhaust systems are specified in the fire code in those areas. An update on applying Computational Fluid Dynamics (CFD) in smoke exhaust design will be presented in this paper. Key points to note in CFD simulations on smoke filling due to a fire in a big hall will be discussed. Mathematical aspects concerning of discretization of partial differential equations and algorithms for solving the velocity-pressure linked equations are briefly outlined. Results predicted by CFD with different free boundary conditions are compared with those on room fire tests. Standards on grid size, relaxation factors, convergence criteria, and false diffusion should be set up for numerical experiments with CFD.

\section{Introduction}

Many fire models have been developed for studying preflashover fire and reported in the literature [1-3]. Computational Fluid Dynamics (CFD) or known as field models $[4,5]$, originally developed for fire simulations, are widely applied in smoke management system design. Development of fire field models started 30 years ago [6-10] at leading institutes all over the world. These are the Building Research Institute [11] and Tokyo University of Science in Japan; Notre Dame University [12] and the Fire Research Centre, National Bureau of Standards [13] in the USA; and the Fire Research Station [14] in the UK. Later, it was known as application of CFD [15] in mid 1990s. This was much widely applied when some of the research CFD softwares became commercial packages. Progress in CFD research for building fire applications was very slow in the past 10 years as explained in above. Most of the efforts were on applying CFD in performance-based design (PBD) on fire safety provisions. Fire Dynamics Simulator (FDS) $[9,10]$ is now commonly used.

Applications are now restricted to only smoke exhaust systems including both static smoke extract system or natural venting, and dynamic smoke extract system with mechanical fans. Building fire is a low-speed chemically reacting flow [16] dominated by buoyancy [17]. Three key fluid flow phenomena $[4,5,16,17]$ on scalar transport are dominated by buoyancy-induced turbulence; heat transfer with thermal radiation at the burning object and the associated combustion chemistry involving hundreds of intermediate chemical reactions $[18,19]$ should be considered at the same time. It is difficult to develop a simple CFD model to include all these three parts realistically without using any simpler models with empirical parameters.

However, there are always difficulties in finding resources for in-depth research as pointed out $[20,21]$. On the other hand, many engineers with some CFD training were recruited as fire engineers for handling $\operatorname{PBD}[22,23]$ on building fire safety. Most of research efforts were therefore spent on applying CFD in building applications and generating beautiful graphics presentation, rather than working or getting more advanced CFD fires.

Therefore, CFD model was only used for designing smoke movement and design of air handling system such as smoke exhaust systems [24] or tunnel ventilation system. 
Although the computing time required is still long, CFD has been improved with efficient numerical schemes. Faster personal computers with larger memory capacity are now available. Fluid flow problems up to 10 millions of computing cells can be accommodated with true 64-bit operating system. However, the computing time still takes several days. Efforts were even made on developing standards on using fire models $[25,26]$, but how?

It was believed $[3,15,27]$ in 1990 s that CFD field model has the greatest potential to simulate building fires as discussed in several classical publications [6-8]. A fire was taken as a heat source generating convective flow by buoyancy. A system of coupled, nonlinear, partial differential equations was set up on conservation of momentum, heat, and mass of smoke induced by fire. Temperature and velocity fields induced by the fire source were predicted. This approach is physical and incorporates basic principles supposed to predict more detailed information with minimum experimental data input. CFD model is good for predicting the thermal environment in big enclosures such as an atrium or a tunnel, though it is less suitable for regions near to a fire. The model should be developed by studying further on thermal radiation, combustion chemistry for common building materials, and turbulent mixing with air. Further, very few experimental verification and validation [28] were reported [28-31]. Most of the experimental data used for justifying CFD results are originally for studying fire zone models [32]. In fact, very limited systematic full-scale experimental works, except some by Ingasson and Olsson [33] on sprinkler fires and natural vents, were specially designed for justifying CFD models. The data reported by Steckler et al. [34] was performed originally for studying the doorway flow, but always used for verifying field models because of having many data at different positions. However, such limited studies did not give any promising results on CFD predictions as indicated by the VVT-FDS [35] study. Validation works were started as a longer-term project by the US Nuclear Regulatory Commission [36]. Therefore, CFD are limited on studying smoke movement in regions far away from the fire, to avoid simulating combustion and thermal radiation effects. Even so, there are always challenges on accepting design based on CFD predictions. Consequently, field tests are required to evaluate whether the system will perform as the design. Atrium hot smoke test [37-41] is then required in many places of the Far East. There are also problems in training sufficient number of government officers, engineers and facilities managers to understand CFD. An updated review on applying CFD in designing smoke exhaust system is presented in the paper.

\section{Smoke Filling}

Fire is taken $[6-8,10]$ as a physiochemical system of momentum, heat and mass transfer. A set of nonlinear and coupled partial-differential equations governing the conservation of momentum, heat, and mass are set up to describe the fire system. Whenever a fire occurs, natural convective flow fields would be generated, with the general form of the conservation law for a time-averaged fluid property. The thermal power from a fire in an enclosure is of the order of megawatt, such as that produced by burning a polyurethane foam sofa. The resultant flow is turbulent and appropriate for the use of turbulence models.

There are three main parts $[4,5]$ in a CFD field model: turbulence in simulating the buoyancy induced motion, discretization of the set of partial differential equations, and algorithms in solving the velocity-pressure linked equations.

CFD predictions are mainly applied for designing smoke exhaust system in big space, particularly in atrium and tunnel. Static smoke extraction system is not so welcome by the Authority. Any change in the surrounding air pressure distribution due to wind or any other thermal perturbations will give very different system performance. Therefore, it is only suitable for small buildings with very low occupant loading, such as air cargo terminals. Performance of static smoke extraction system in crowded spaces such as shopping malls and public transport interchanges, particularly those located in deep underground, should be justified seriously by fire science and engineering. The scenario of pushing smoke down from air above must be demonstrated by full-scale burning tests that it would not happen. The design should not be accepted without such justification.

Other parameters including numerical parameters for stability and convergence such as relaxation factors, convergence criteria, residuals, and time steps, and parameters concerned in free boundaries, orifice coefficient of the openings, and how long the computing domain has to be extended to outside from an opening must be justified. Values of all these parameters should be selected very carefully with experiment. Different problems should be simulated by "trial and error" numerical experiments first.

\section{Turbulence Model}

Two common approaches $[6,10]$ were used to simulate turbulent flow. These are the Reynolds Averaging of NavierStokes Equation (RANS) method and Large Eddy Simulation (LES).

The time-averaged values of the air flow variables including the momentum, density, pressure, enthalpy, and smoke concentration are solved using RANS. Any instantaneous value for these variables $\phi_{t}$ is expressed as its time-averaged value $\phi$ plus the fluctuation $\phi^{\prime}$. The set of equations describing conservation laws on $\phi_{t}$ can be transformed in terms of $\phi$ with the product of the fluctuation terms $\phi^{\prime}$ for different flow variables separated out. Different turbulent models (e.g., [6]) have been proposed to close the set of equations to make it look similar to those for $\phi_{t}$, but the diffusion coefficient concerned becomes an effective value which is much greater than the laminar one. The $k-\varepsilon$ model family of turbulent model is commonly used in simulating fire-induced flow fields. Time averages of the velocity vector components $u, v, w$ (in a Cartesian coordinate system), the enthalpy $h$ and the turbulence parameters $k$ and $\varepsilon$ are then taken as $\phi$. There are many CFD packages based on RANS available in the literature in the 1990s. Commercial software was used to 
have a preprocessor menu for putting in building geometry. Because of the hardware limitation, CFD model based on RANS had been applied for designing smoke management systems in big halls and tunnels. However, there are criticisms on the accuracy due to grid size and boundary condition. The model cannot simulate combustion realistically and hence to predict carbon monoxide and soot concentrations in a fire.

In LES, turbulent motion is decomposed as large- and small-scale motions by filtering. The large-scale flow structures are calculated numerically by solving the differential equations concerned. Small-scale motions are modeled by subgrid-scale Reynolds stresses (e.g., [10]). The first step of LES is filtering. A flow variable $\phi(\vec{x}, t)$ at position $\vec{x}$ and time $t$ is decomposed into a large-scale component $\bar{\phi}(\vec{x}, t)$ and a small-scale (subgrid-scale) component $\phi^{\prime}(\vec{x}, t)$. The large-scale component $\bar{\phi}(\vec{x}, t)$ is a spatial average through a function $G\left(\vec{x}-\vec{x}^{\prime}, \Delta\right)$ in the domain of interest $\Omega$ through a filter width $\Delta$ as

$$
\bar{\phi}(\vec{x}, t)=\int_{\Omega} G\left(\vec{x}, \vec{x}^{\prime}, \Delta\right) \phi\left(\vec{x}^{\prime}, t\right) \overrightarrow{d x^{\prime}} .
$$

The choice of the filter function is important. LES approach would require much more computing cells than the RANS. There were discussions before that RANS with similar number of computing cells would give similar predictions by LES. LES is now commonly used in fire simulations. However, treatment of fire boundary should be watched.

There are many physical empirical parameters in both approaches. Values of empirical parameters $C_{1}, C_{2}, C_{3}, C_{\mu}$ and $C_{D}$ used in RANS $k-\varepsilon$ model [6] had already led to argument. These parameters are suggested to be tuned for different flow problems. But doing this would take CFD as a curve-fitting exercise [42]. The parameter $C_{s}$ in the subgridscale model in using LES [43] is important.

\section{Finite Volume Method}

The set of partial differential equations describing the flow variable $\phi$ is commonly solved by the Spalding-Patankar control volume method $[6,7]$. This is a finite difference method with the equations discretized by integration over a control volume. Special attention is paid to the convective part which depends on the flow direction. All these have been discussed clearly in the literature and will not be repeated in detail here.

Different schemes are available in discretizing the equations with the finite volume (or control volume) method. Common differencing schemes in fire simulations $[6,20,44]$ are the upwind scheme, the hybrid scheme, the power law scheme, and the second-order Quadratic Upstream Interpolation for Convective Kinematics (QUICK) scheme [44]. The central differencing scheme was tested to have difficulties in getting converged results in fire simulations $[15,45]$.

The upwind differencing scheme is equivalent to the zeroth-order interpolation with the choice of interfacial values depending on the sign of velocity. It is first-order accurate in terms of the Taylor series truncation error. Solution of the discretized equations based on this scheme is comparatively stable, seldom diverge or oscillate. Therefore, numerical schemes based on stable first-order upwinding are popular in studying convective transport. However, the firstorder accuracy makes it prone to numerical diffusion errors. False diffusion is a multidimensional phenomenon explained by taking the three-dimensional flow on each cell boundary as a one-dimensional flow. It occurs when the flow is oblique to the grid lines and when there is a nonzero gradient of the dependent variable in the direction normal to the flow. Such errors appear when the difference scheme fails to account for the true direction of the flow. Both the upwind and central difference schemes are not able to satisfy this requirement.

The false diffusion errors can be minimized by employing higher-order discretization. Scheme with second-order accuracy would involve a third-derivative truncation error. This becomes a source of unphysical oscillations under high convection conditions. Many schemes having higher order accuracy have been proposed to handle false diffusion. Those schemes involve discretization improvements in the simple upwind representation of the convection term. The QUICK scheme (e.g., [44]) is a popular one which uses a threepoint upstream-weighted quadratic interpolation for each interface. The resulting finite difference equation is thirdorder accurate based on Taylor series analysis. This is a thirdorder accurate upwind difference scheme with additional control volume cells involved in the interpolation which will reduce diffusion errors to a certain extent by bringing in a wider influence. The scheme possesses the stability of firstorder upwinding but is free of its second-order numerical diffusion.

\section{Velocity-Pressure-Linked Equations}

There is no explicit equation to calculate air pressure distribution in a CFD model. However, pressure gradients appear in the momentum conservation equation. Staggered grid system with the pressure (and other scalar quantities) nodes coincided with the cell faces of the control volume for velocity component is used for solving the equations. In this way, the pressure gradient can be represented properly for flows with oscillating pressure. Further, the velocity components are calculated at the exact locations for computing other scalar quantities.

The velocity components $u, v$, and $w$ can be computed once the pressure field is known. But these computed velocity components might not satisfy the continuity equation. The Semi-Implicit Method for Pressure-Linked Equations (SIMPLE) algorithm was proposed for solving this problem $[6,44]$. This is an important step in developing CFD. Since there is no explicit equation for calculating the pressure field, pressure distribution pattern has to be guessed at the beginning. Therefore, SIMPLE required long computing time if the guessed pressure distribution is different from the reality. Modifications of the scheme were proposed for fire simulations. Three common algorithms $[46,47]$ including the SIMPLE-Revised (SIMPLER), the noniterative Pressure Implicit with Splitting of Operators (PISOs); and the iterative PISOs were tested before on fire simulation for solving the velocity-pressure linked equations of the above problem [45]. 
The standard $k-\varepsilon$ turbulent model was employed for describing the turbulent effect. Numerical experiments were performed in simulating the fire-induced flow and temperature in the large test room reported by Ingason and Olsson [33]. The predicted results using the three algorithms were compared with the experimental data. The results show that iterative-type solution method is good for fire field modeling. Solutions predicted from the original noniterative PISO algorithm might not satisfy the continuity equation; but give preliminary estimation for fire engineering application as computation time required is very much reduced. The treatment of free boundary conditions for the cases studied is important in achieving a reasonably steady-state solution.

For reducing computing time and memory demand, the solution domains were usually confined in the fire compartment. The boundary condition for pressure $P$ along $x$-direction was set to

$$
\left(\frac{\partial P}{\partial x}\right)=0
$$

However, reasonably steady-state results could not be obtained in this way. The flow field predicted used to be strong. In fact, the predicted mass drawn in and flow out from the compartment seems to be increasing indefinitely. One explanation for this phenomenon is that the fire source is located very close to the door opening where the free boundary conditions cannot be assumed. In order to overcome this problem, the solution domain must be extended to include the free space near the left door to a sufficient distance that the error due to the inaccuracy of boundary conditions was kept to minimum. In that study, the free boundary was extended to the outside air of the compartment. In this way, the neutral plane height can be predicted. But the computing time and memory requirement would be much longer and larger.

The noniterative PISO scheme, though much less computation time is required for the simulation, is not reliable enough where accurate results are desirable. The iterative PISO method is commonly applied for fire simulations though SIMPLER [7] also gives good results.

\section{The Fire Dynamics Simulator}

After releasing version $3.01[9,10]$ by the Building and Fire Research Laboratory, National Institute of Standards and Technology (NIST), USA in late $2002[48,49]$ after almost 30 years of research, FDS is then actively upgraded. It is now a popular fire engineering tool. Compressible fire-induced air flow can be simulated with hot smoke taken as a thermally expandable gas. A set of governing equations suitable for simulating fluid flow induced by buoyancy with a low Mach number have been derived. The Boussinesq approximation is no longer necessary and constraints on inviscid fluid have been removed. The FDS model allows larger variations of both density and temperature. An important assumption is that the pressure variation is small, so that the ideal gas law can be approximated by decomposing the pressure into a "background" component, a hydrostatic component, and a flow-induced perturbation.
This assumption is reasonable for flows with low Mach number because the temperature is inversely proportional to density. The pressure in the state and energy equation is replaced by the background pressure to filter out sound waves of speed much faster than the typical flow speeds expected in a compartment fire. The momentum equations were rearranged based on the assumption that vorticity generation due to buoyancy prevails over its generation due to the baroclinic effect. Short turbulence length scale will be simulated by LES with the Smagorinsky subgrid models.

Turbulence, intermediate combustion chemistry and thermal radiation have to be included instantaneously to study the heat released from combustion. Combustion chemistry should be incorporated properly in FDS. There have been studies on intermediate chemistry for polymethyl methacrylate (PMMA), polyvinyl chloride (PVC), polyurethane foam (PUF), and wood. Possible reaction kinetics from the predicted mixing with oxygen and temperature were studied. The chemical reactions of combustion for PMMA are very complex with intermediate reactions classified under the seven groups on thermal decomposition; thermal oxidative decomposition; decomposition of monomer MMA; methane combustion; methanol combustion; formaldehyde oxidation and acetylene combustion. For the group of methane combustion [19], 77 intermediate reactions were identified. This reaction identification process had been reported for the other six groups. Such reactions will be reviewed carefully for identifying the important ones such as those generating heat. Only those key reactions are considered to be put into FDS.

The Smagorinsky constant $C_{s}$ in the subgrid-scale model used in FDS has to be evaluated [43]. The boundary layer is not so important for this scale. The coefficient $C_{s}$ is varying from 0.1 to 0.25 . Values of the Smagorinsky constant $C_{s}$ would affect the results related to the grid refinement predicting indoor airflow. For coarser grids, a larger value of $C_{s}$ would give better results. For fire simulations, $C_{s}$ was selected as 0.2. Another important coefficient, the subgridscale turbulent Prandtl number $P_{r t}$, is varying from 0.2 to 0.9 as reported $[50,51]$. Results for fire simulations are not very sensitive to changes in $P_{r t}$, taken as 0.5 [51] for simulating the indoor airflow.

The mixture fraction model $[48,49]$ is used in FDS to describe the fire burning process, and the model is based on the assumption that combustion is mixing-controlled. Each chemical specie of interest is described by a mixture fraction, which is a conserved quantity representing the fraction of its specie at a given position originating from the fuel. The mass fraction of each species is related to the mixture fraction by "state relations" from where necessary information can be extracted. For example, the state relation for the oxygen mass fraction would be used to calculate the local oxygen mass consumption rate. The local heat release rate can then be computed from the local oxygen consumption rate by assuming that it is directly proportional to the oxygen consumption rate and independent of the fuel involved. This procedure will be reviewed for its suitability in dealing with combustion chemistry. 


\section{Verification and Validation}

CFD predicted results are always queried. A detailed analysis on quantifying the modeling and numerical uncertainties in those fire simulations is therefore required [28]. Within the last decade, the quality or credibility of CFD fire simulations has drawn increasing attention from the society of fire engineering. The procedures for assessing the credibility of fire simulation codes are not agreed [52].

The term verification and validation $(\mathrm{V} \& \mathrm{~V})$ was used in operations research with definitions of $V \& V$ reviewed [28]. Implementation of V\&V for credibility quantification in CFD field model is studied in the preliminary stage. Some available CFD fire codes do not go through cautious tests of $\mathrm{V} \& \mathrm{~V}$, their work can only be regarded as just a demonstration that some special fire scenarios are probably simulated. This situation persists in the arena of CFD fire modeling, especially for the sector of CFD commercial codes [53]. One of the possible reasons is that there is no commonly accepted $\mathrm{V} \& \mathrm{~V}$ methodology available, though at least three different standards on the credibility of CFD have been published $[28,51]$.

In contrast to zone models which have been well validated by experiments [15], to the best knowledge of the author, experimental validations of field models have not been carried out to the same extent as for zone models. In fact, very limited experimental work, except some by Ingasson and Olsson [33] on sprinkler fires and natural vents, have been performed for verifying field models. Experimental data reported by Steckler et al. [34] originally for studying doorway flow have been used many times for verifying field models [29].

There are validation documents on FDS and on other models released by the US Nuclear Regulatory Commission. Seven volumes of the draft report have just been made available [36]. A series of 25 fire tests were conducted with primary purpose to provide data to validate computer models for nuclear power plant. The experiments were conducted in an enclosure of size $18 \mathrm{~m}$ by $12 \mathrm{~m}$ with height $6 \mathrm{~m}$. The fires consisted of a simple gas burner, heptane or methanol liquid pools, or a PMMA solid fire. Four of the tests were conducted with a full-scale control room mockup in place. Parameters including the fire intensity, enclosure ventilation rate, and fire location were varied during the experiments.

Full-scale burning facilities should be developed for verifying and validating CFD results. Some on FDS had been reported [54]. An exhaust hood fitted with a fanduct system is necessary to measure the heat release rate of burning combustibles by the oxygen consumption method. Different scenarios should be set up by burning combustibles of different sizes at different locations and ventilation conditions. Air temperature and velocity of the induced fire flow should be measured together with the heat release rate of the fire.

\section{Functional Analysis}

Functional analysis [55] was proposed to justify the CFD predicted results better. This is better than just saying the agreement between predictions and measured values is "good" or "bad." This method was proposed as a quantitative, statistical and analytical approach to evaluating fire zone models $[32,56]$ first, and applied to verify CFD models [57]. The transient measured $\left(t_{i}, m_{i}\right)$ and predicted $\left(t_{i}, p_{i}\right)$ curves are denoted by two vectors $\vec{m}$ and $\vec{p}$ by summing up all the $n$ data points $m_{i}$ and $p_{i}$ at different time intervals $t_{i}, i=1, \ldots, n$ vectorally. The vector $\vec{m}-\vec{p}$ will give the deviation. Two parameters were defined to give a quantitative measure on the similarity of the curve shape.

(i) The "norm" is the normalized relative distance between the vectors $\vec{m}$ and $\vec{p}$. As recommended by Peacock et al. [55], the Euclidean "norm" for $n$ data is calculated by $m_{i}$ and the corresponding $p_{i}$ at $t_{i}$ with $\mathrm{s}$ data points used to smoothen the fluctuating curves to provide better estimates inside as

$$
\operatorname{norm}=\frac{|\vec{m}-\vec{p}|}{|\vec{m}|}=\frac{\sqrt{\sum_{i=1}^{n}\left(m_{i}-p_{i}\right)^{2}}}{\sqrt{\sum_{i=1}^{n}\left(m_{i}\right)^{2}}}
$$

(ii) The parameter "cosine" (or "inner product") is defined as the angular difference between the resultant vectors as

$$
\begin{aligned}
\text { cosine } & =\frac{\langle\vec{m}, \vec{p}\rangle}{|\vec{m}| \cdot|\vec{p}|} \\
& =\frac{\sum_{i=2}^{n}\left(m_{i}-m_{i-s}\right)\left(p_{i}-p_{i-s}\right) / s^{2} \mathcal{A}}{\sqrt{\sum_{i=2}^{n}\left(m_{i}-m_{i-s}\right)^{2} / s^{2} \mathcal{A} \sum_{i=2}^{n}\left(p_{i}-p_{i-s}\right)^{2} / s^{2} \mathcal{A}}},
\end{aligned}
$$

where $\mathcal{A}$ denotes $\left(t_{i}-t_{i-1}\right)$.

The "norm" approaches zero and the "cosine" approaches 1 when the two curves are very close to each other.

\section{An Example Case Study}

Quality experiments on smoke filling were reported by Hägglund et al. [58], Li and Chow [59]. A single-storey building of floor area $11 \mathrm{~m}$ by $39 \mathrm{~m}$ and height $8 \mathrm{~m}$ as shown in Figure 1 was considered. The wall and ceiling were constructed by mineral wool, and the floor was concrete. There were three vents labeled D1, D2, and D3, each of area $2.2 \mathrm{~m}$ by $0.6 \mathrm{~m}$ on the top of the front wall. The upper edge of the openings was positioned $0.2 \mathrm{~m}$ below the ceiling level. Two air inlets $\mathrm{A} 1$ and $\mathrm{A} 2$ of area $1 \mathrm{~m}$ by $2 \mathrm{~m}$ were at the lower edge of the left wall and front wall as shown in Figure 1.

The fires were positioned in the center of one half of the building. Methanol was used as the fuel and was burnt in square steel pans of sizes $0.56 \mathrm{~m}^{2}$ and $2.0 \mathrm{~m}^{2}$. The heat release rate per unit horizontal area of the fuel was $440 \mathrm{kWm}^{-2}$. Hot air movement was observed by discharging smoke. The gas temperature was measured by thermocouples distributed over four vertical lines with $50 \mathrm{~cm}$ spacing as shown in 


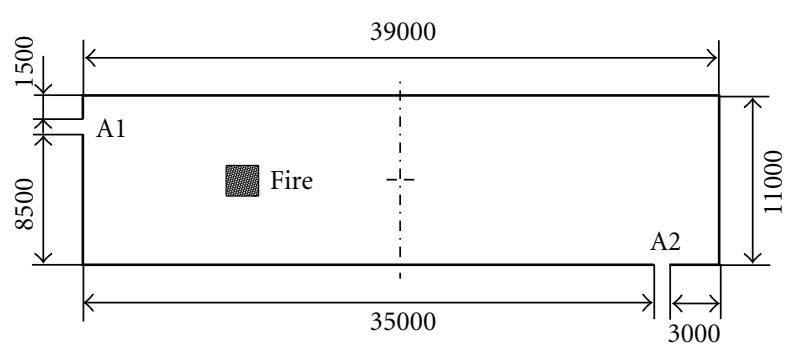

(a) Plan

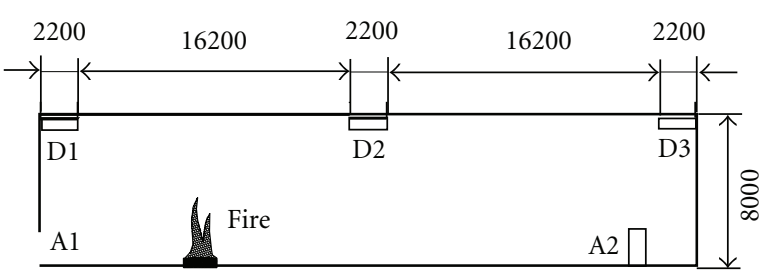

(b) Elevation

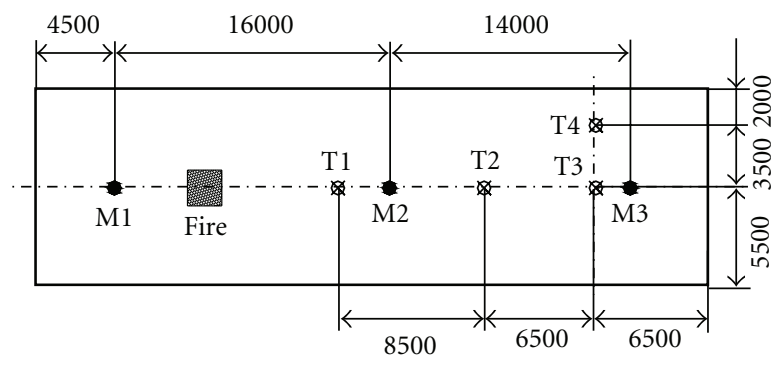

Thermocouples

- Measuring scales

(c) Locations of thermocouples and measuring scales

Figure 1: The test room.

Figure 1(c). Two video cameras were used to record the descending of smoke layer.

Two tests on smoke filling were selected to be simulated by CFD model FDS4. Smoke filling of two large room fire tests with and without wind outside the test room were studied. The numerical experiments are labeled as Cases 1 and 2 as follows.

Case 1. Fire size: $2.0 \mathrm{~m}^{2}$

Internal air temperature: $15^{\circ} \mathrm{C}$

External air temperature: $8^{\circ} \mathrm{C}$

External wind: $0 \mathrm{~ms}^{-1}$

Cubic grid of size: $0.2 \mathrm{~m} \times 0.2 \mathrm{~m} \times 0.2 \mathrm{~m}$

Total number of grids: 429,000 .

Case 2. Fire size: $0.56 \mathrm{~m}^{2}$

Internal air temperature: $13^{\circ} \mathrm{C}$

External air temperature: $3^{\circ} \mathrm{C}$

External wind: $6 \mathrm{~ms}^{-1}$

Cubic grid of size: $0.2 \mathrm{~m} \times 0.2 \mathrm{~m} \times 0.2 \mathrm{~m}$

Total number of grids: 975,000 .

The heat release rate per unit area of the fuel was $440 \mathrm{kWm}^{-2}$. The growth period of the mass burning rate was set to $60 \mathrm{~s}$. The input heat release rate curves are shown in Figure 2. The maximum heat release rates were $880 \mathrm{~kW}$ and $246.4 \mathrm{~kW}$ for Cases 1 and 2, respectively.

Four thermocouple trees labeled $\mathrm{T} 1$ to $\mathrm{T} 4$ were set as in Figure 1(c). Predicted air temperatures for Case 1 are compared with experimental results in Figures 3(a) to 3(d).

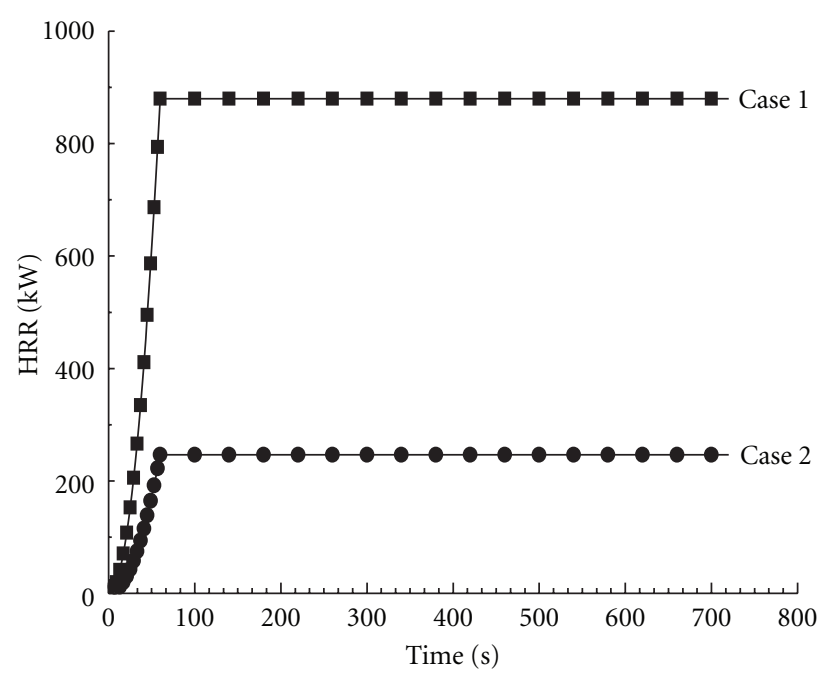

Figure 2: Input heat release rates.

It can be seen that the two curves matched better with each other at height $4 \mathrm{~m}$ above floor, but not so good for $6 \mathrm{~m}$ above floor in the four thermocouple trees. At $6 \mathrm{~m}$ above floor, the predicted temperature increased more rapidly than experiment.

Hot smoke layer height results at M1, M2, and M3 are shown in Figure 4(a). Three predicted curves were all kept steady at about $3 \mathrm{~m}$ above floor and fluctuated in a small scale. The smoke layer height measured in experiment was 


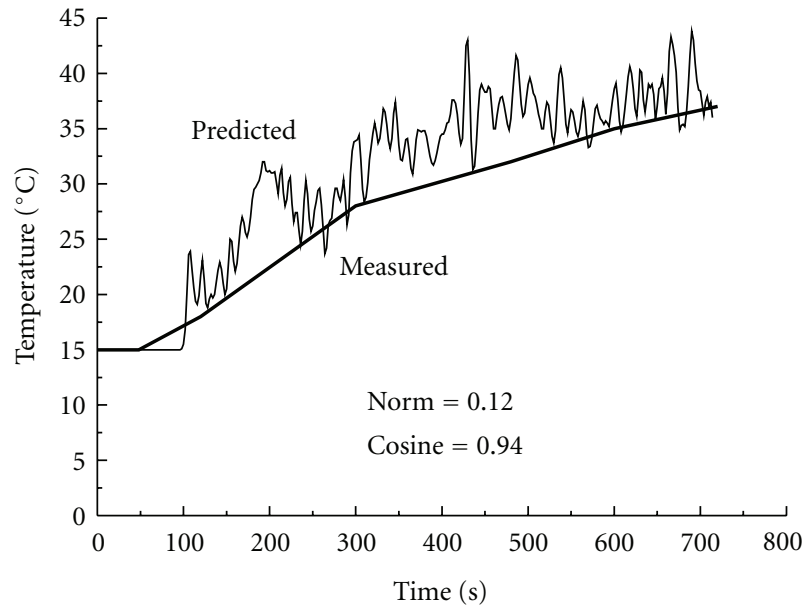

$4 \mathrm{~m}$ above floor

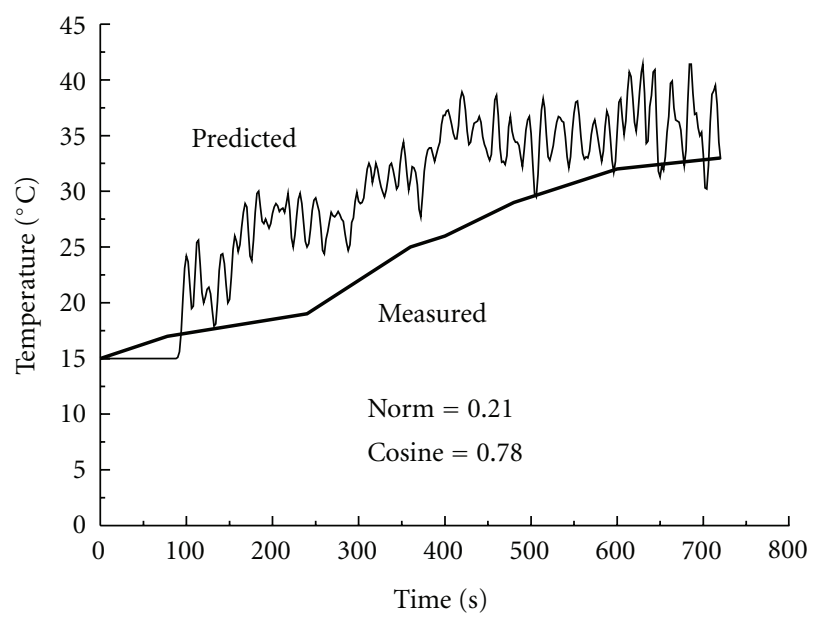

$4 \mathrm{~m}$ above floor

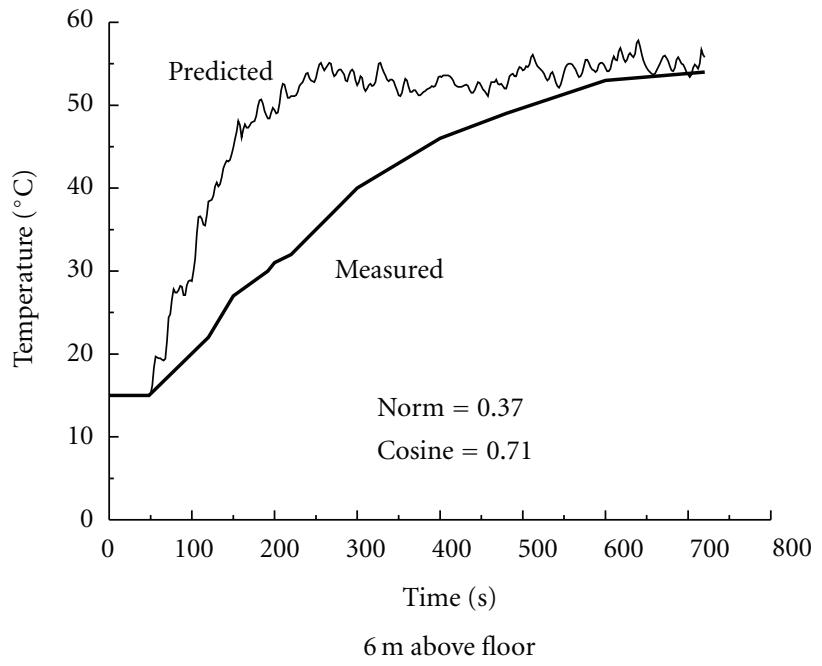

(a) $\mathrm{T} 1$

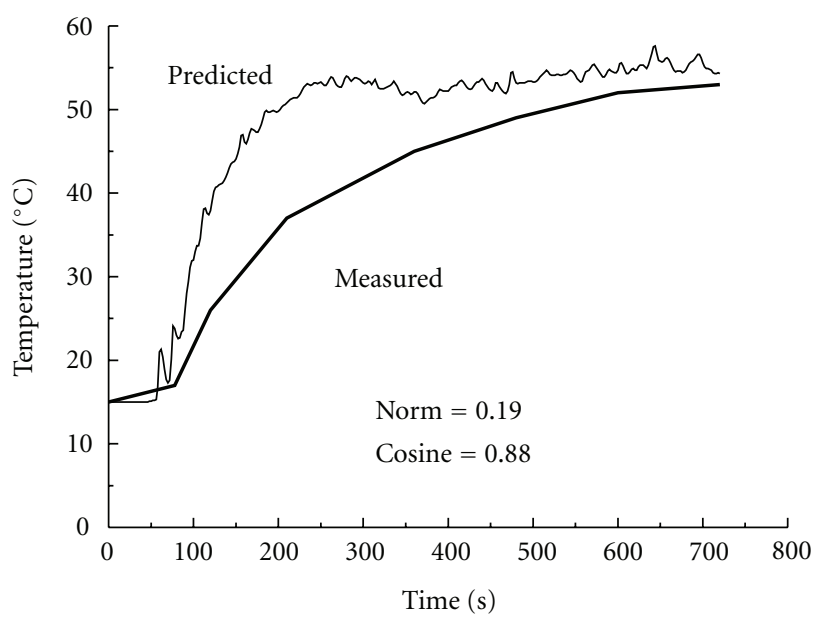

$6 \mathrm{~m}$ above floor

(b) $\mathrm{T} 2$
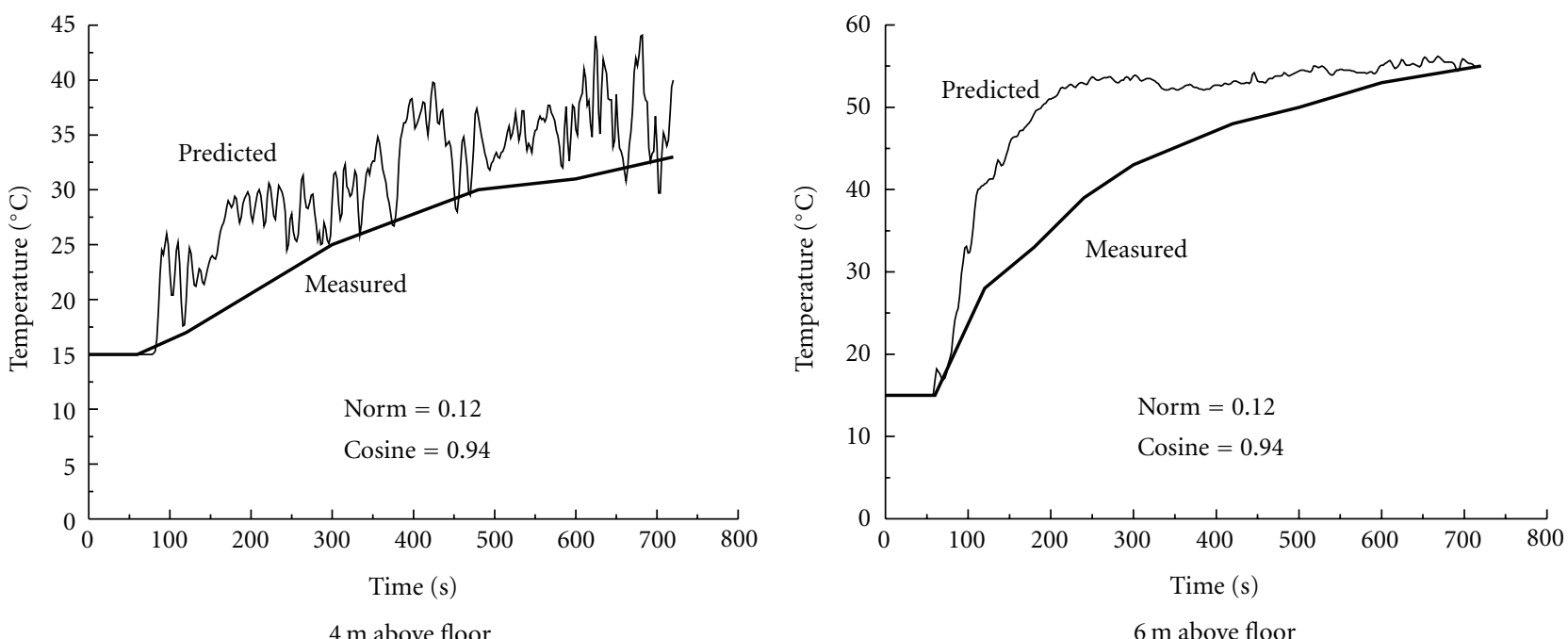

(c) $\mathrm{T} 3$

Figure 3: Continued. 


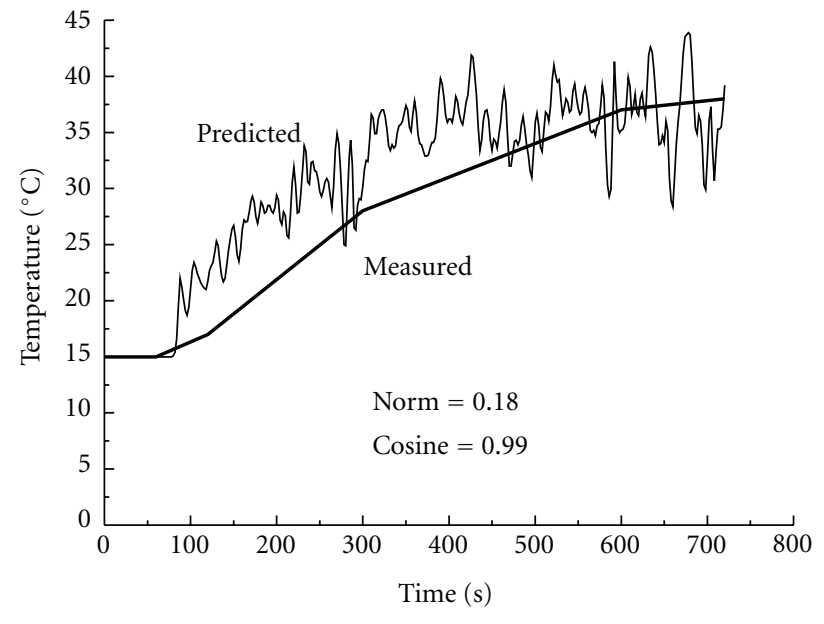

$4 \mathrm{~m}$ above floor

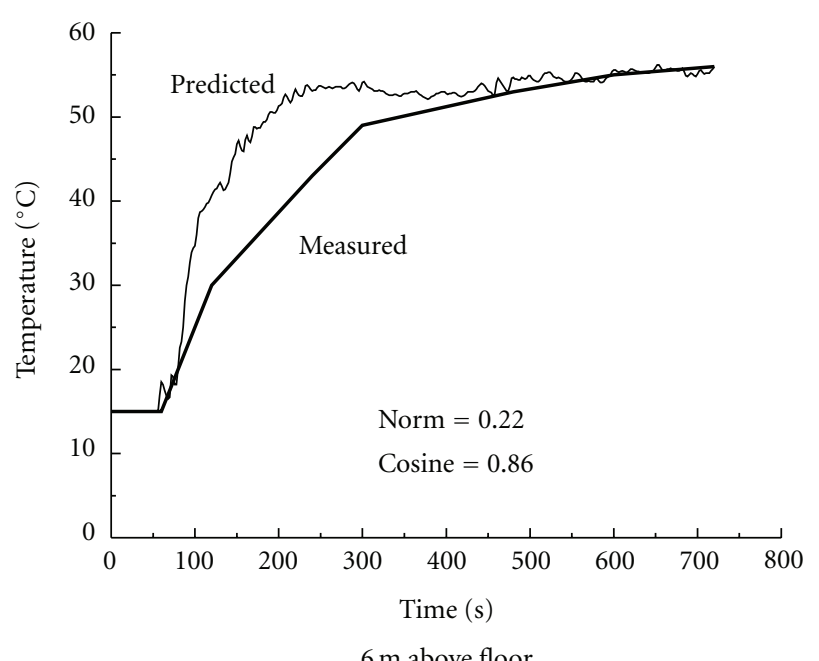

$6 \mathrm{~m}$ above floor

(d) $\mathrm{T} 4$

Figure 3: Air temperature of Case 1.

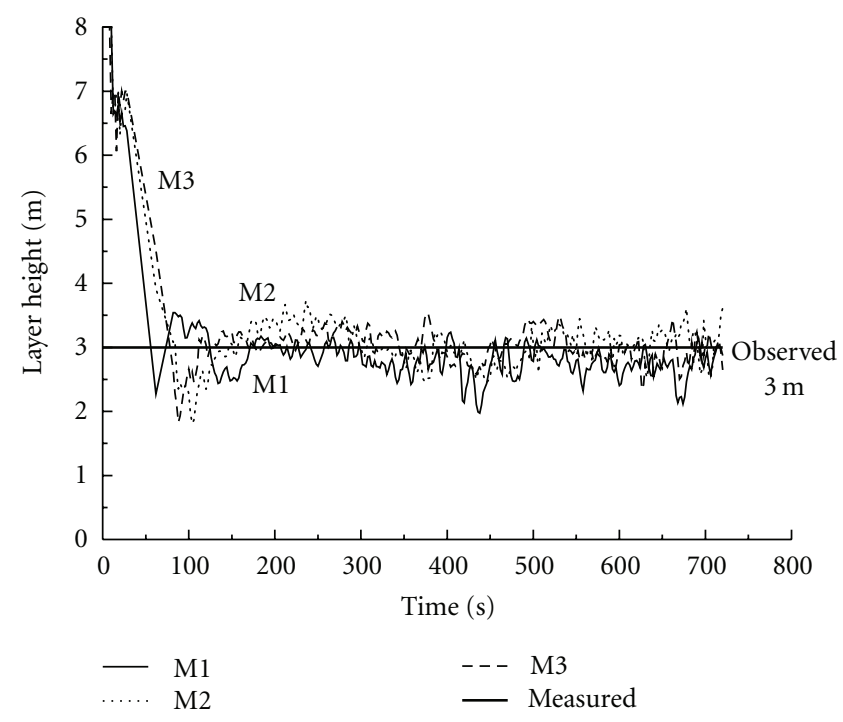

(a) Case 1

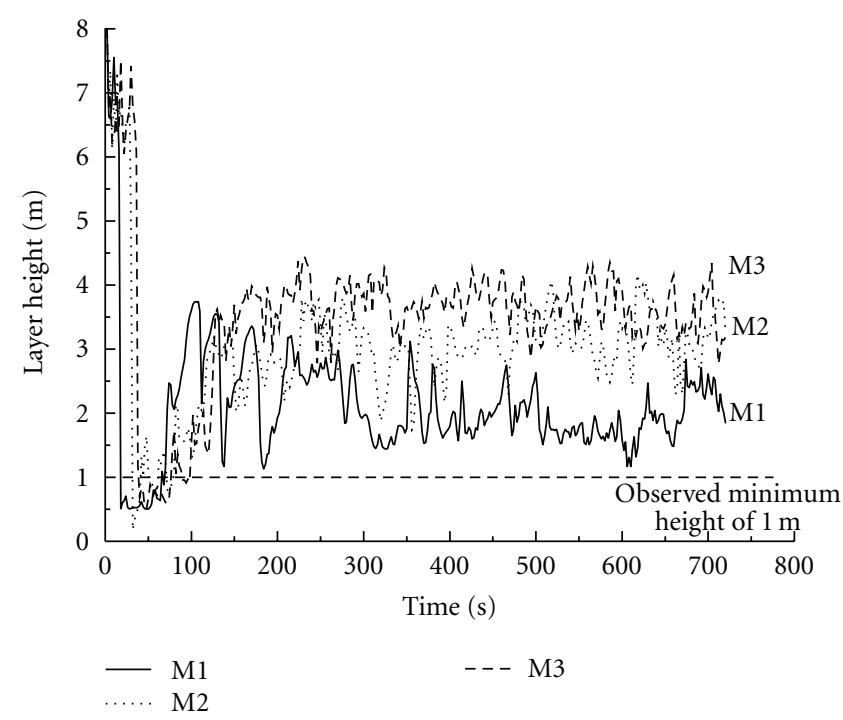

(b) Case 2

Figure 4: Smoke layer height.

just $3 \mathrm{~m}$ above floor. It appears that the predicted smoke layer height is reasonably good.

Predicted temperatures of Case 2 are shown in Figures 5(a) and 5(b). As the heat release rate of Case 2 was smaller than that of Case 1, two positions at $6 \mathrm{~m}$ and $7 \mathrm{~m}$ above floor on each thermocouple tree were compared. The predicted air temperature curve agreed well with experiment. The CFD tool FDS appears to be good for simulating the fire scenario with wind effect.

Predicted smoke layer heights at M1 to M3 are shown in Figure 4(b). The smoke layer of Case 2 fluctuated more vigorously than that of Case 1. A possible explanation is due to wind outside. Smoke layer height at M1 fluctuated, particularly near to the left inlet.
Observed descending of the smoke layer in the experiment was reported [58] to be about $1 \mathrm{~m}$. Smoke fell down to the top of the vertical inlet vent at height $1 \mathrm{~m}$. There were three vents near to the ceiling. Hot smoke exhausted through two vents at the ceiling, and air was sucked into the room through the third one close to the fire as shown in Figure 6. Predicted velocity vector profile across vents is also shown in Figure 6. As shown in Figure 6(b), the air flow velocity vector at the two vents on the right was towards the inside of the room, while at the left vent it was opposite. This was the same as what reported in the tests [58]. Predicted air temperature and smoke layer interface height were compared with the test results by applying functional analysis. Air temperature predictions in Figures 3 and 5 were 


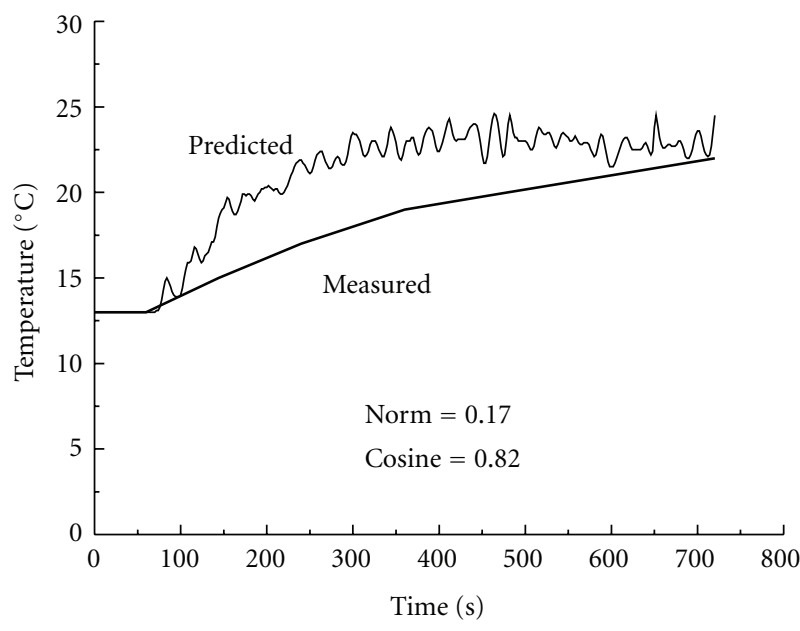

$6 \mathrm{~m}$ above floor

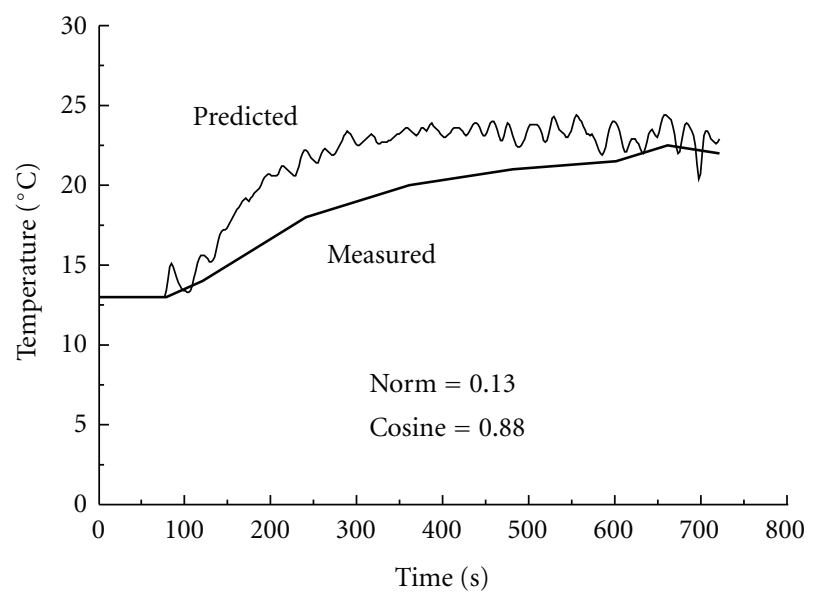

$6 \mathrm{~m}$ above floor

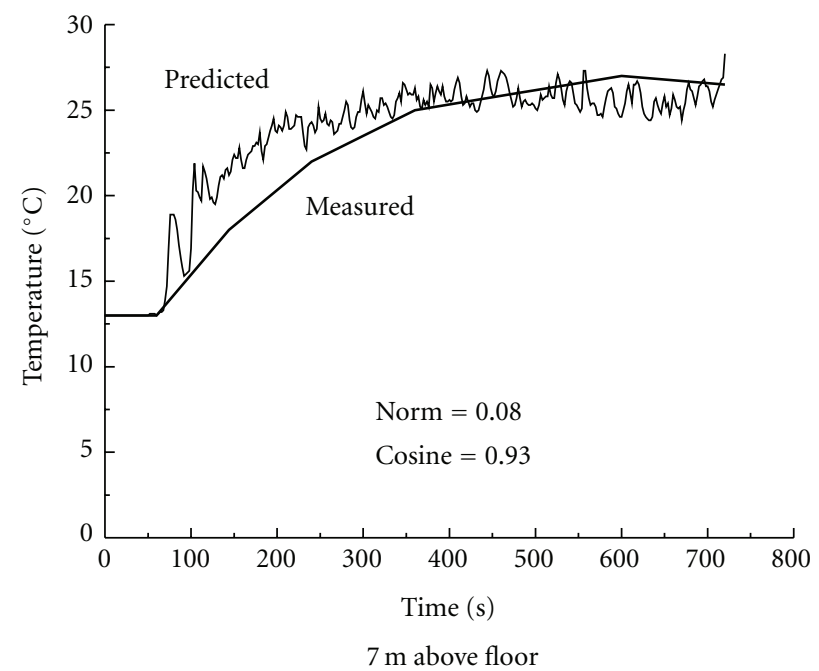

(a) $\mathrm{T} 1$

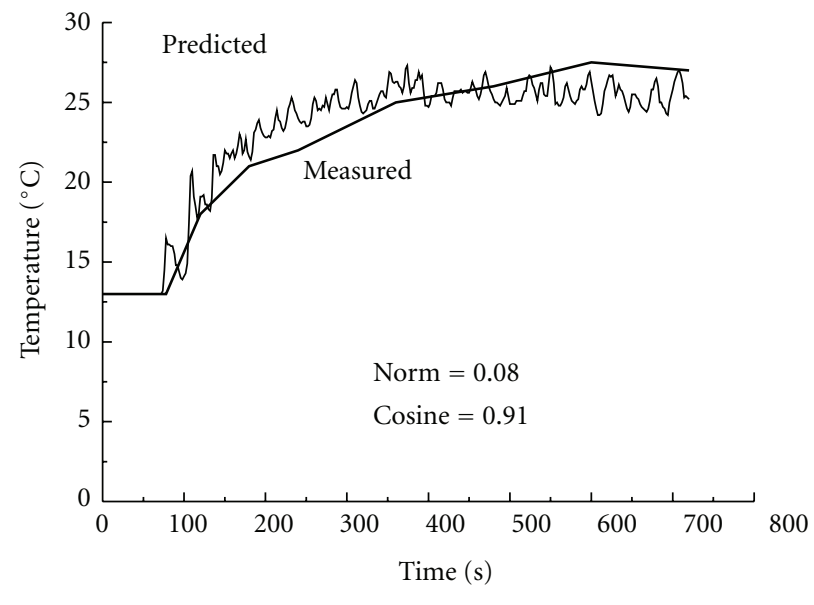

$7 \mathrm{~m}$ above floor

(b) $\mathrm{T} 2$

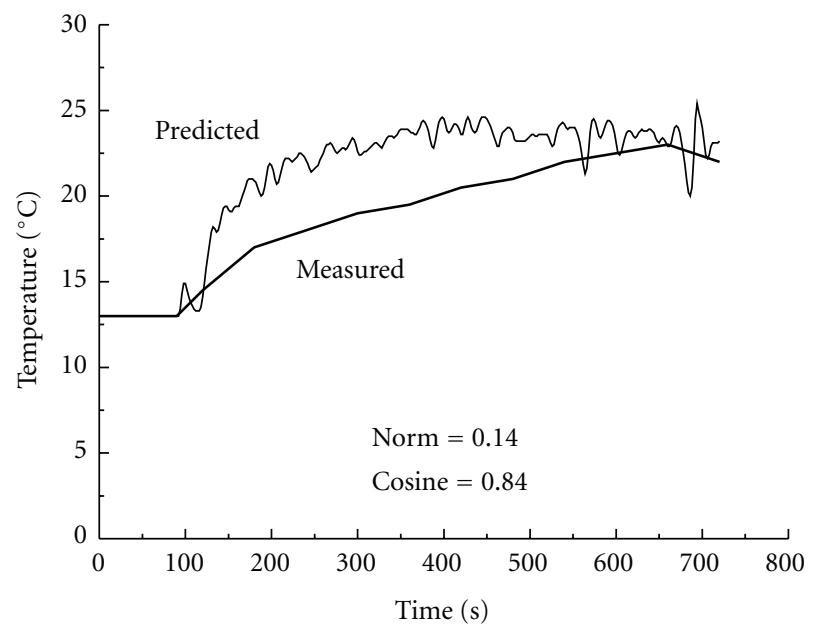

$6 \mathrm{~m}$ above floor

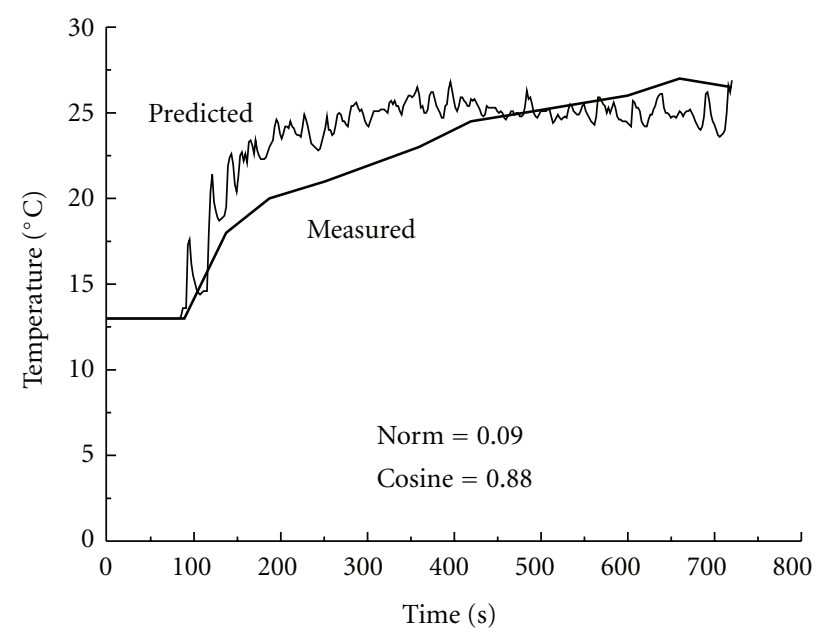

$7 \mathrm{~m}$ above floor

(c) $\mathrm{T} 3$

Figure 5: Continued. 


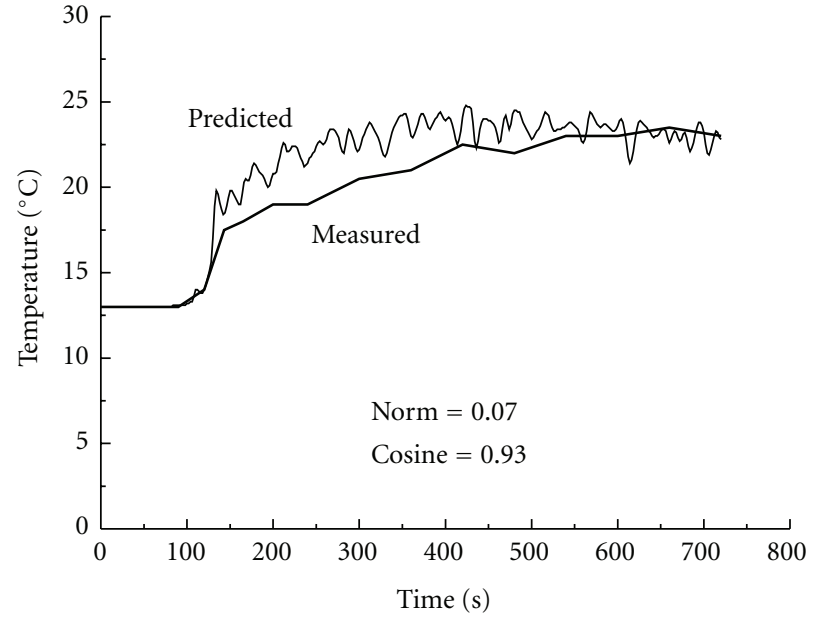

$6 \mathrm{~m}$ above floor

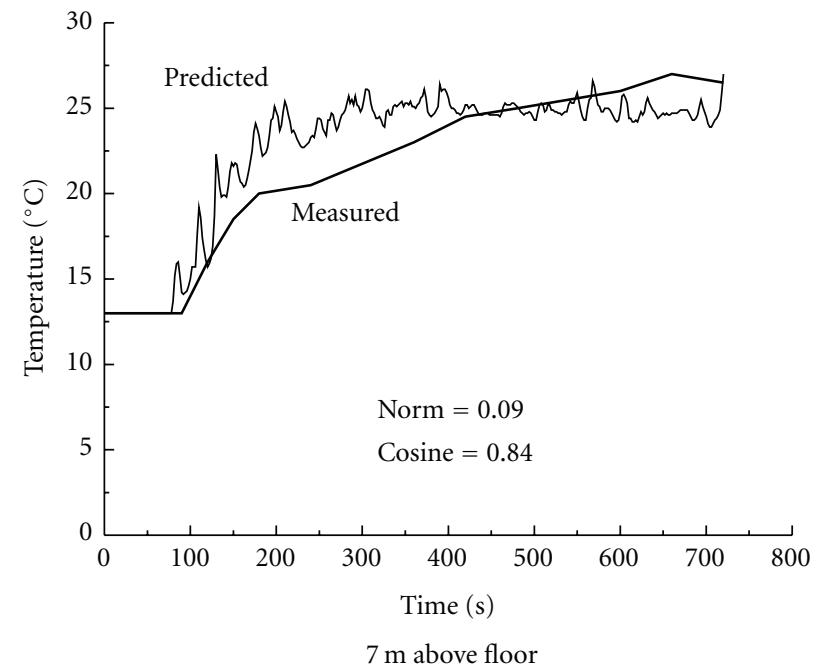

(d) $\mathrm{T} 4$

Figure 5: Air temperature of Case 2.

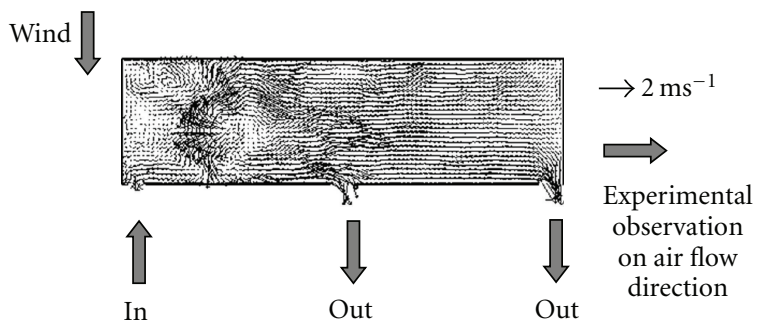

FIgure 6: Predicted velocity vector across a plane with vents for Case 2.

justified by taking $n$ to be 8 and $s$ as 2 . Results on norm and cosine are shown also in the figures. For Case 1, FDS predictions gave norms from 0.08 to 0.37 , and cosines from 0.71 to 0.99 . In Case 2, the norms were from 0.07 to 0.14 , and cosines from 0.82 to 0.93 . CFD results predicted at some positions were satisfactory and very close to those measured values. For example, norm of T4 at $4 \mathrm{~m}$ above floor is 0.01 , approaching to 0 . Cosine is 0.95 with value close to 1 . However, the predicted results were fairly acceptable at some positions with large deviations. For predictions at T1 with $6 \mathrm{~m}$ above the floor, norm is 0.37 and cosine is 0.71 . Further, predicted air temperatures increased faster than the observed rate in the test. More vigorous justification of fire models is necessary before using them. Therefore, CFD fire models should be improved for application on fire protection design and evaluation [60].

A scaling system can be set up based on the values of norm and cosine on key flow variables to denote how good the CFD predicted results agree with experiment. However, this cannot be only set up by research workers. Authorities with responsibility to accept fire safety provisions for PBD $[22,23]$ should play the key role in deciding whether to use a 3-point scale (bad, neutral, and good) or a 5-point scale (very bad, bad, fairly good, good and very good).

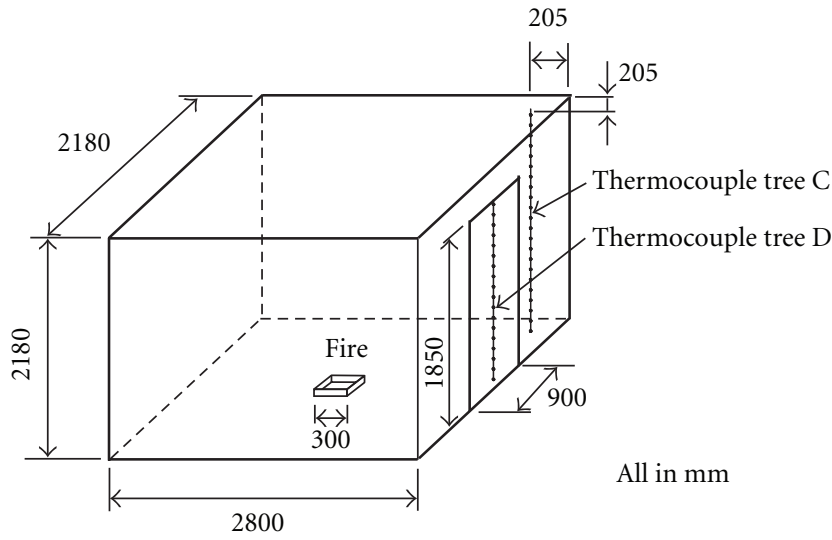

FIGURE 7: Test room by Steckler et al. [34].

\section{Free Boundary Conditions}

In applying CFD to building fire hazard assessment, there are always windows and doors open to outside. Bi-directional flow would be observed experimentally, with hot gas flowing out and cool air coming into the room. There are many debates on specifying free boundary conditions for such openings. Flow parameters, particularly the pressure, have to be specified carefully. There are empirical correlations relating the pressure profiles across the vertical openings such as windows or doors, under different room geometries, heat release rates of the fires, and opening sizes. However, such boundary conditions might not give proper specification. A better approach is to extend the computing domains outside, as pointed out years ago by Schaelin et al. [60] in 1992 for simulating plume flow, and Mawhinney et al. [29] on fire studies in 1994. This part should be watched carefully as pointed out again before [21]. 


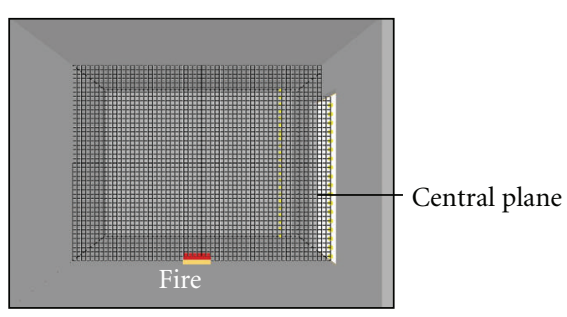

(a) FB1

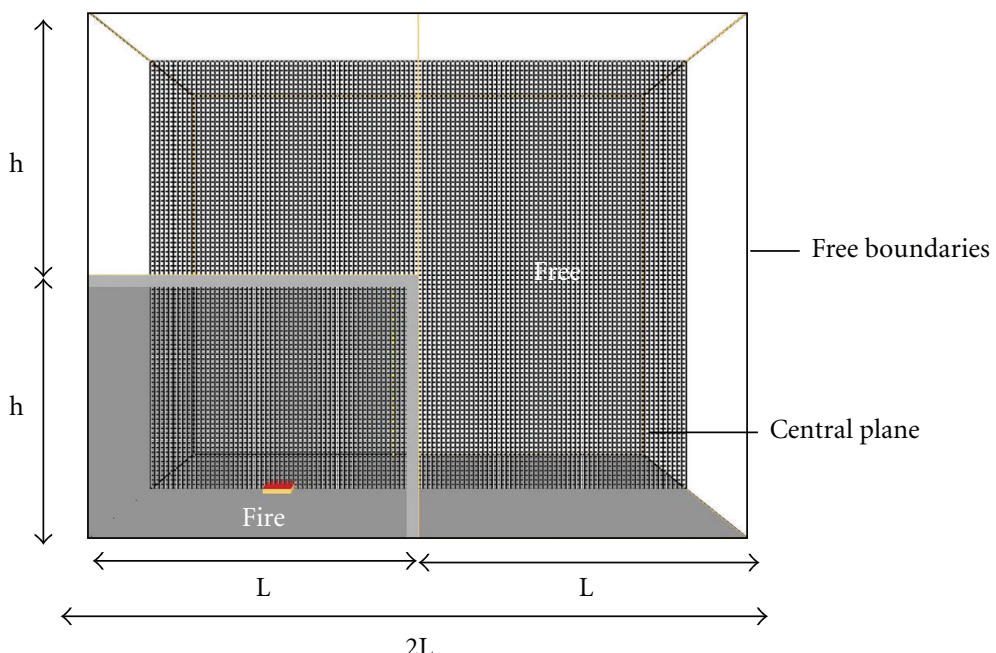

$2 \mathrm{~L}$

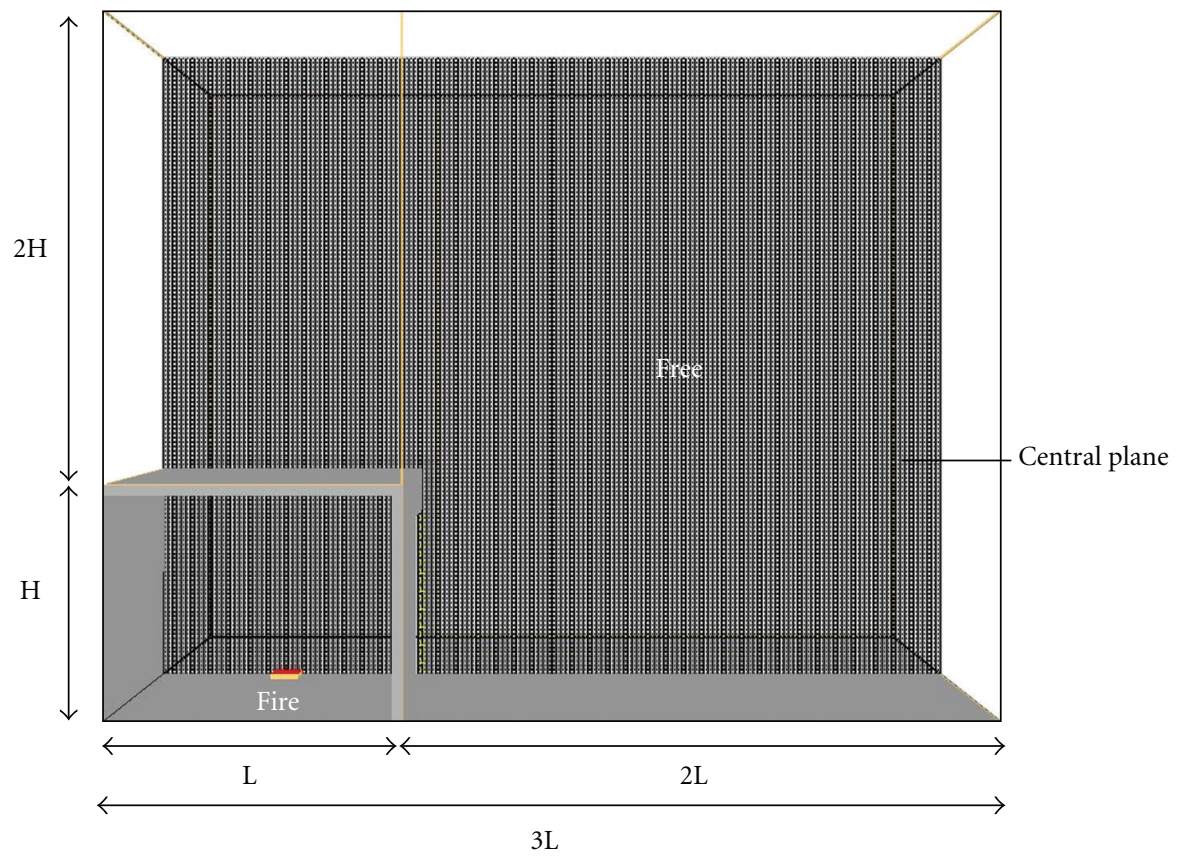

(c) FB3

Figure 8: Three free boundary conditions.

The fire tests reported by Steckler et al. [34], $\mathrm{Li}$ and Chow [61] in a room of area $2.8 \mathrm{~m}$ by $2.8 \mathrm{~m}$ and height $2.18 \mathrm{~m}$ as shown in Figure 7 were taken as an example. A $0.3 \mathrm{~m}$ square methane burner of heat release rate $62.9 \mathrm{~kW}$ was placed at the centre of the test room. A door of width $0.9 \mathrm{~m}$ and length $1.85 \mathrm{~m}$ was located at the centre of the side wall. Two thermocouple trees, $\mathrm{C}$ and $\mathrm{D}$, each with 22 probes, were placed at the corner and the doorway, respectively. Vertical air temperature profiles from floor to ceiling were measured at these two thermocouple trees.

Taking into account the accuracy and the computing time, cubic grids of size $0.05 \mathrm{~m}$ by $0.05 \mathrm{~m}$ by $0.05 \mathrm{~m}$ were used in CFD simulations with FDS. The room was divided into a grid system of 246,400 cells with 100 by 56 by 44 parts along the $x$-, $y$-, and $z$-directions, respectively, in the FDS input file. Three free boundary conditions labeled as FB1, FB2, and FB3 were tested in FDS simulations.

For free boundary condition FB1, FDS menu for free openings was used without extending the computing domain to outside. Air flow parameters at the open boundary depend on whether the flow is outgoing or incoming [34]. Taking air pressure $P$ as an example, $P$ is related to horizontal velocity $u$ by

$$
P= \begin{cases}\frac{|u|^{2}}{2}, & \text { outgoing } \\ 0, & \text { incoming. }\end{cases}
$$




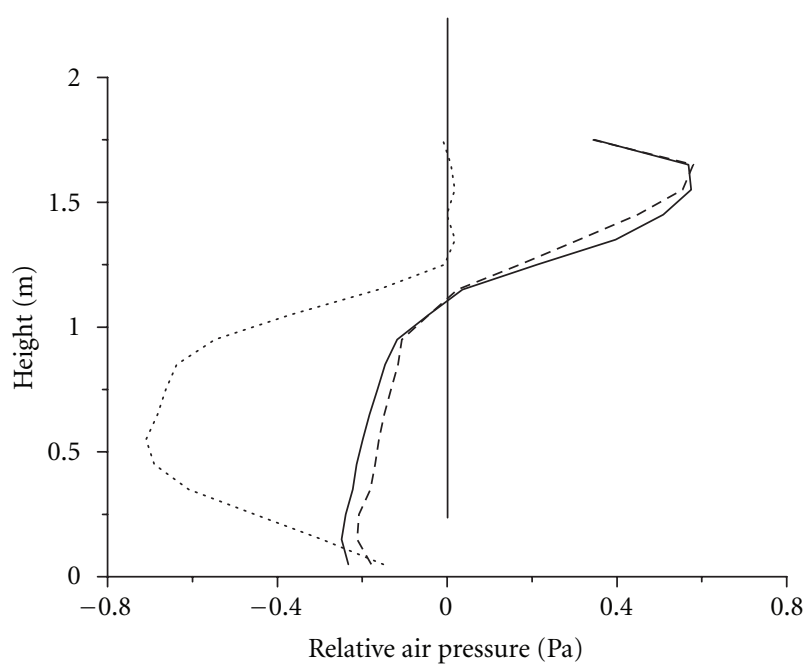

(a) $100 \mathrm{~s}$

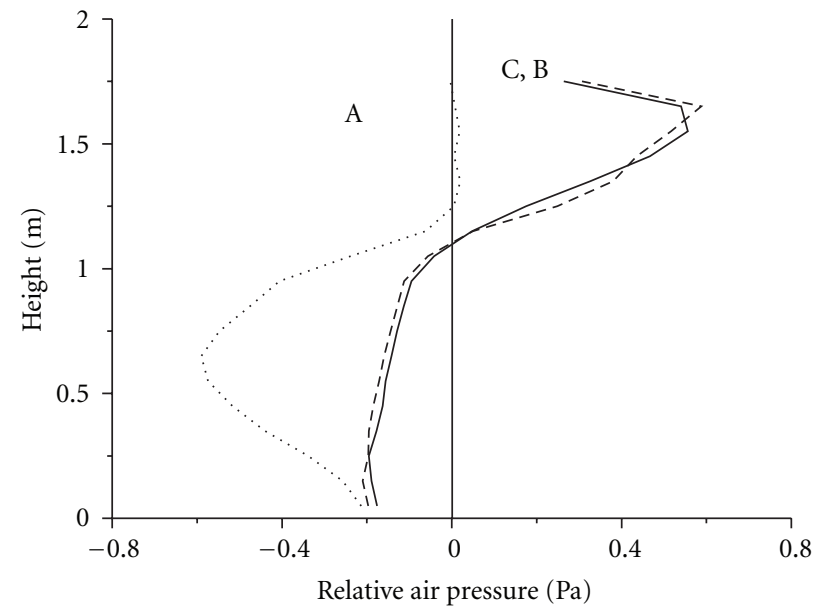

(b) $150 \mathrm{~s}$

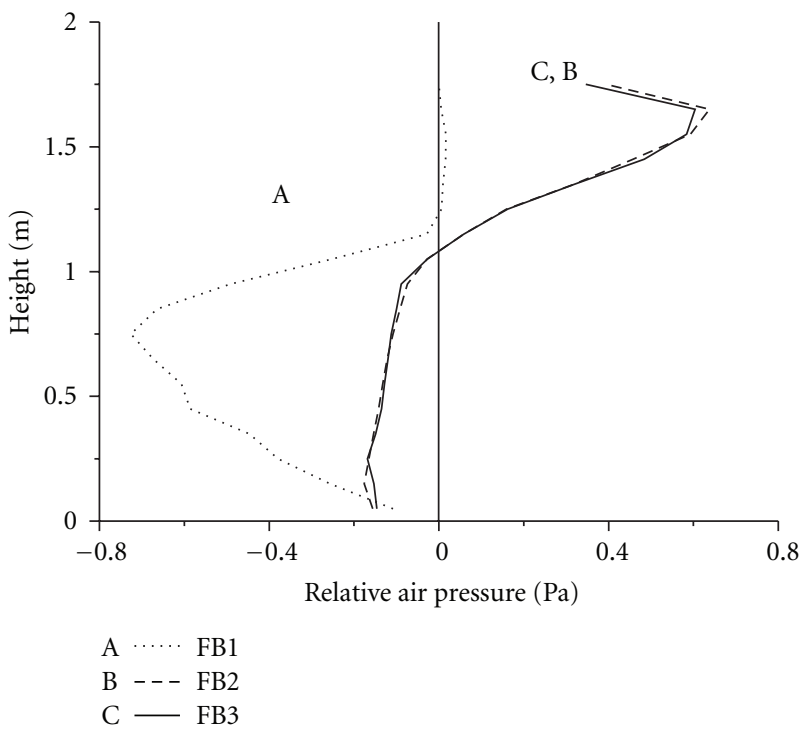

(c) $200 \mathrm{~s}$

Figure 9: Relative air pressures at doorway.

The outgoing boundary condition assumes that the pressure perturbation is zero at an outgoing boundary and that $P$ is constant along streamlines. The incoming boundary condition assumes that $P$ is zero infinitely far away. At the boundary between two meshes, the pressure boundary condition is similar to that at an external open boundary. But $P$ is taken from the adjacent mesh where the flow is incoming.

The lengths and heights of the extended space were once or twice of the room length and height, respectively, for FB2 and FB3. The input geometries of FDS simulations for these three boundary conditions are shown in Figure 8.

Relative air pressures with respect to ambient values at the doorway and horizontal components of velocity at $100 \mathrm{~s}, 150 \mathrm{~s}$, and $200 \mathrm{~s}$ are shown in Figures 9 and 10. Air temperatures at different height at the corner in the room are shown in Figure 11. In applying functional analysis to compare with measured air temperature, values of norm for simulations FB1, FB2, and FB3 are $0.015,0.013$, and 0.013 respectively, and values of cosine are $0.59,0.58$, and 0.57 respectively. Predicted air temperatures are very close to experiments using the three boundary conditions. All have low values of cosine. However, the pressure profiles across the door were entirely different in view of Figure 9. It is difficult to accept the predicted pressure profiles of FB1, though experimental pressure data were not available on that set of tests. Predicted values are not so satisfactory as in the first example of simulating smoke filling in a bigger hall. A possible explanation is because combustion plays a key role in simulating fire in a small room. Further investigation would be worked on simulating the combustion process in CFD fire models. 


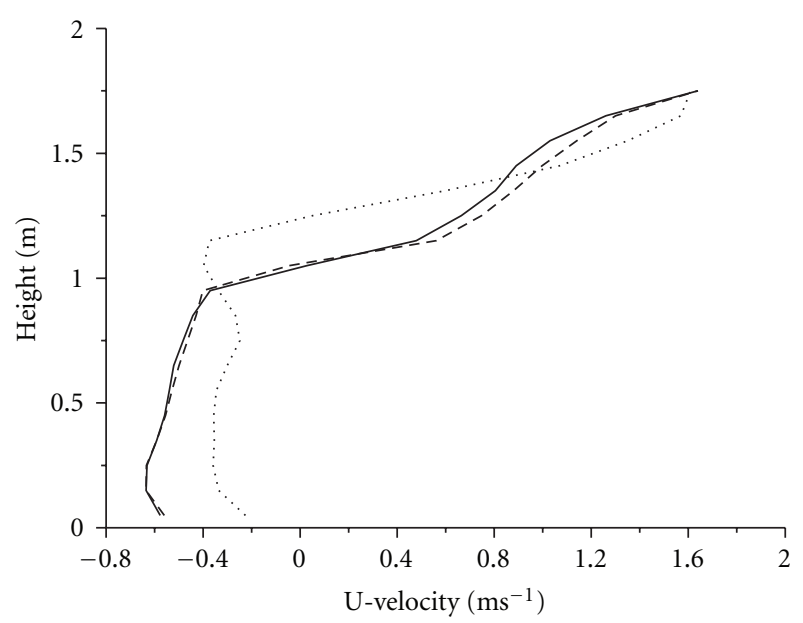

(a) $100 \mathrm{~s}$

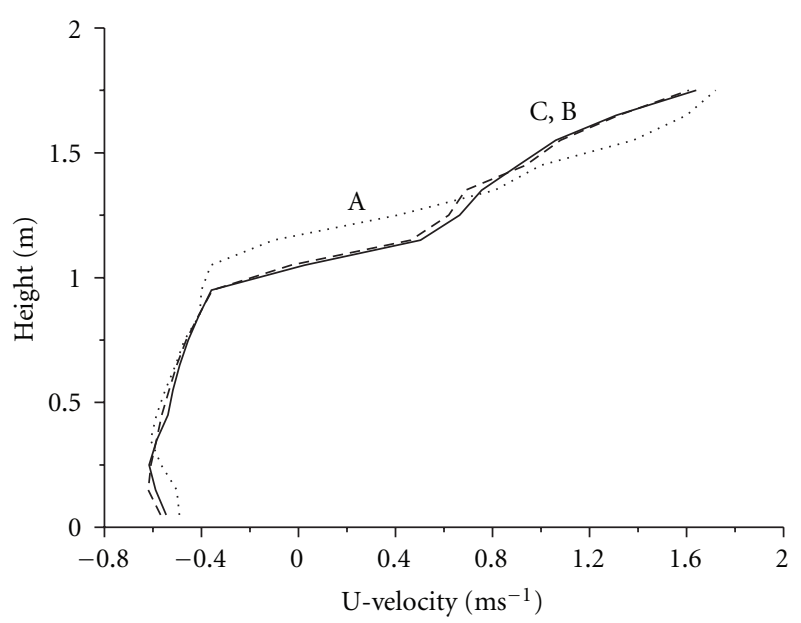

(b) $150 \mathrm{~s}$

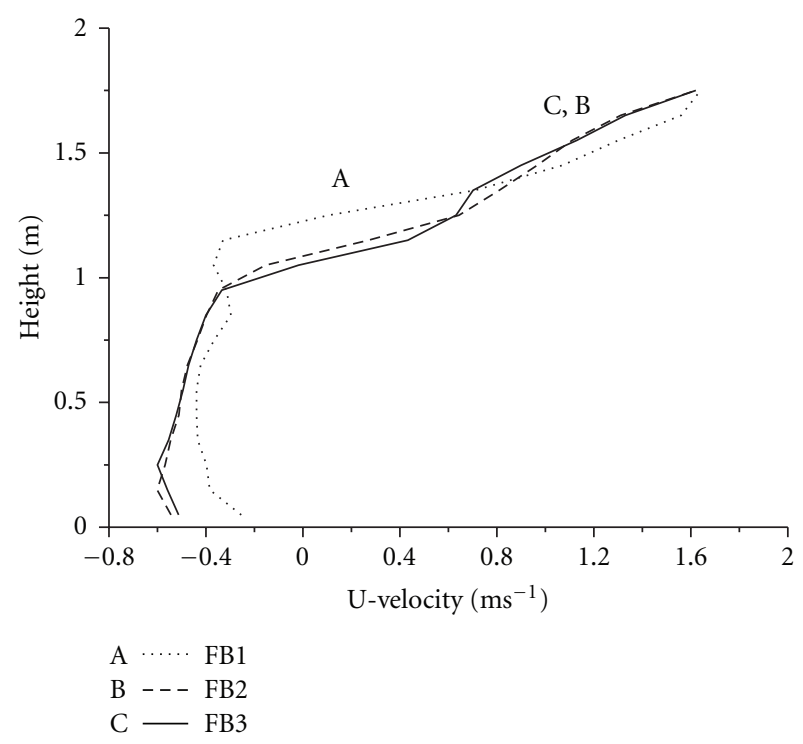

(c) $200 \mathrm{~s}$

FIGURE 10: Horizontal velocity components at doorway.

\section{Conclusions}

Although CFD has been used in designing smoke exhaust systems in those atria [37-41] for over 30 years, not many studies were devoted to simulate turbulent mixing, intermediate combustion chemistry, and thermal radiation realistically without using empirical formula. Further, there were very few verification and validation works on the predicted results with limited full-scale burning tests, especially designed for CFD fire models. Fire engineers are then required to justify the CFD results while testing and commissioning the smoke exhaust systems [62]. Hot smoke tests in the atrium site [37-41] are therefore required to evaluate the performance of atrium smoke exhaust systems in many places including Hong Kong.

Fire models had been used in many projects but led to many arguments and debates on some submodels of those available tools. If the results are not demonstrated clearly, say by full-scale burning test, the process would appear as a "curve-fitting exercise." "Verification" exercises might be necessary, in addition to "engineering judgment." Although the associated costs for carrying out the burning tests might be high, it is necessary for some projects to demonstrate that adequate fire safety is provided.

Engineering tools with CFD models are applied in fire safety engineering. There are many reasons why the CFD field model is so attractive. The predicted "microscopic" picture of the thermal environment described by the velocity vector diagram, the temperature, pressure and smoke concentration (taken as mass of chemical specie) contours are useful for deriving the relevant macroscopic parameters for engineering purposes. The calculated vertical distribution of air temperature is useful in providing the appropriate thermal sensitivity for sprinkler heads. Also, the air entrainment rates for a fire plume were calculated from the predicted horizontal velocity components. 


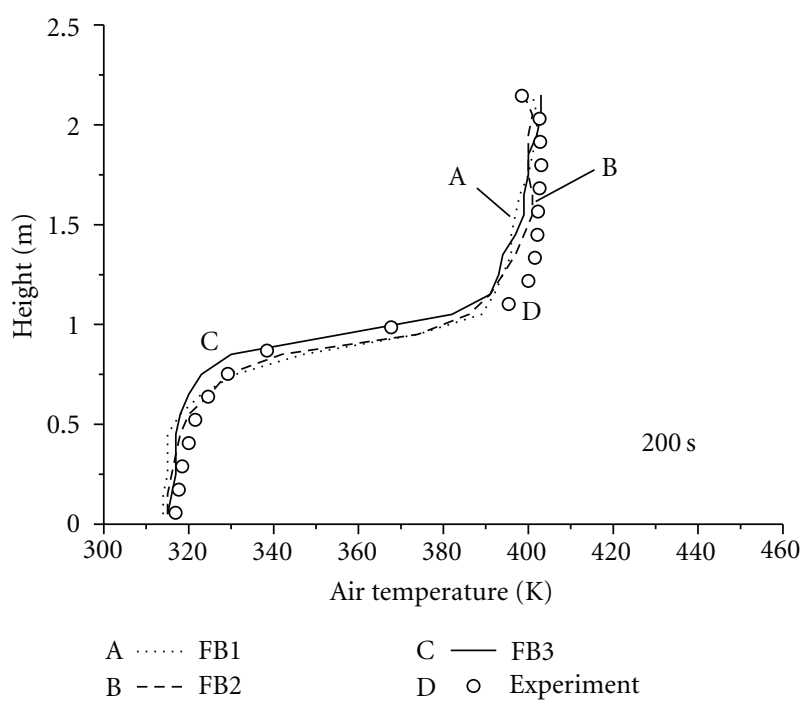

FIgURE 11: Air temperatures at $200 \mathrm{~s}$ by thermocouple tree C.

There is still room for improving the accuracy of those engineering tools. Verification and validation of those models is particularly important. As pointed out in Hong Kong [62], both building designers and relevant government officials should be properly trained in using fire models. Note that the development of fire model itself is very rapid. For example, three-dimensional simulations with CFD models can be handled readily with a personal computer now. But 20 years ago, only two-dimensional simulations could be carried out in a mainframe computer.

Relevant education and training must be provided [63, 64]. Offering degree programmes up to MSc level is necessary for upgrading the quality of fire engineering personnel. At least, continued professional development programmes are recommended to be offered regularly.

FDS $[48,49]$ is very suitable in fire safety engineering. However, there is still much development to do and careless application of the technique would lead to wrong results. Verification and validation studies such as those works started by the US Nuclear Regulatory Commission [36] are important. Full-scale burning tests [61, 62] for validating CFD fire field models are necessary.

\section{Nomenclature}

$\begin{array}{ll}C_{s}: & \begin{array}{l}\text { Smagorinsky coefficient in LES } \\ \text { model }\end{array} \\ C_{1}, C_{2}, C_{3}, C_{\mu}, C_{D}: & \begin{array}{l}\text { Empirical parameters in RANS } \\ \text { model }\end{array} \\ G\left(\vec{x}-\vec{x}^{\prime}, \Delta\right): & \text { Filtering function } \\ h: & \text { Enthalpy } \\ k: & \text { Turbulence parameter } \\ \vec{m}: & \text { A vector representing measured data } \\ m_{i}: & \text { Measured data points } \\ n: & \text { Index in functional analysis }\end{array}$

$\begin{array}{ll}P: & \text { Air pressure } \\ P_{r t}: & \begin{array}{l}\text { Subgrid-scale turbulent Prandtl } \\ \text { number }\end{array} \\ p_{i}: & \text { Predicted data point } \\ \vec{p}: & \text { A vector representing predicted data } \\ t: & \text { Time } \\ u, v, w: & \text { Velocity vector components } \\ \vec{x}: & \text { Position vector } \\ \varepsilon: & \text { Turbulence parameter } \\ \Delta: & \text { Filter width } \\ \phi: & \text { Time averaged value of flow variables } \\ \phi_{t} \text { or } \phi(\vec{x}, t): & \text { Transient flow variables } \\ \phi^{\prime} \text { or } \phi^{\prime}(\vec{x}, t): & \text { Fluctuation of flow variables } \\ \Omega: & \text { Domain of interest. }\end{array}$

\section{References}

[1] G. Cox, Combustion Fundamentals of Fires, Academic Press, London, UK, 1995.

[2] M. L. Janssens, An Introduction to Mathematical Fire Modeling, Technomic Publishing, Lancaster, Pa, USA, 2nd edition, 2000.

[3] W. K. Chow, "Thermal engineering tools in performancebased design for fire safety," Heat Transfer Engineering, vol. 29, no. 9, pp. 757-762, 2008.

[4] G. Cox, "Turbulent closure and the modeling of fire by using computational fluid dynamics," Philosophical Transactions of the Royal Society A, vol. 356, pp. 2835-2854, 1998.

[5] V. Novozhilov, "Computational fluid dynamics modeling of compartment fires," Progress in Energy and Combustion Science, vol. 27, no. 6, pp. 611-666, 2001.

[6] D. B. Spalding, "Mathematical modelling of fluid mechanics, heat transfer and chemical reaction processes," Computational Fluid Dynamics Unit Report HTS/80/1, Imperial College of Science \& Technology, London, UK, 1980.

[7] S. V. Patankar, Numerical Heat Transfer and Fluid Flow, McGraw Hill, New York, NY, USA, 1980.

[8] G. Cox and S. Kumar, "Computer modeling of fire," BRE Information Paper 2/83, Building Research Development, London, UK, 1983.

[9] K. B. McGrattan, H. R. Baum, and R. G. Rehm, "Large eddy simulations of smoke movement," Fire Safety Journal, vol. 30, no. 2, pp. 161-178, 1998.

[10] H. R. Baum, "Large eddy simulations of fires-from concepts to computations," Fire Protection Engineering, no. 6, pp. 36-42, 2000.

[11] Y. Hasemi, "Numerical calculation of the natural convection in fire compartment," Research Paper 69, Building Research Institute (Japan), 1977.

[12] A. C. Ku, M. I. Doria, and J. R. Lloyd, "Numerical modelling of unsteady buoyant flows generated by fire in a corridor," in Proceedings of the 16th International Symposium on Combustion, p. 1373, The Combustion Institute, Pittsburgh, Pa, USA, 1977.

[13] H. R. Baum, R. G. Rehm, and G. W. Mulholland, "Computation of fire induced flow and smoke coagulation," in Proceedings of the 19th International Symposium on Combustion, vol. 19, pp. 921-931, The Combustion Institute, Pittsburgh, $\mathrm{Pa}$, USA, 1982.

[14] N. C. Markatos, M. R. Malin, and G. Cox, "Mathematical modelling of buoyancy-induced smoke flow in enclosures," International Journal of Heat and Mass Transfer, vol. 25, no. 1, pp. 63-75, 1982. 
[15] W. K. Chow, "Use of computational fluid dynamics for simulating enclosure fires," Journal of Fire Sciences, vol. 13, no. 4, pp. 300-334, 1995.

[16] W. K. Chow, "Combustion effect on a building fire field model," in Transport Phenomena on Heat and Mass Transfer, J. A. Rezies, Ed., vol. 2, pp. 1203-1212, Elsevier, Amsterdam, The Netherlands, 1992.

[17] S. R. Tieszen, "On the fluid mechanics of fires," Annual Review of Fluid Mechanics, vol. 33, pp. 67-92, 2001.

[18] H. Tuovinen, "Modelling of laminar diffusion flames in vitiated environment," in Proceedings of the 4th International Symposium of Fire Safety Science, Ottawa, Canada, 1994.

[19] W. R. Zeng, S. F. Li, and W. K. Chow, "Review on chemical reactions of burning poly(methyl methacrylate) PMMA," Journal of Fire Sciences, vol. 20, no. 5, pp. 401-433, 2002.

[20] K. McGrattan, "Fire modeling - where are we now, and where are we going?" in Proceedings of the 8th International Symposium on Fire Safety Science, Tsinghua University, International Association for Fire Safety Science, Beijing, China, September 2005.

[21] C. L. Chow and W. K. Chow, "A brief review on applying computational fluid dynamics in building fire hazard assessment," in A Chapter in Fire Safety, I. Søgaard and H. Krogh, Eds., Nova Science Publishers, 2009.

[22] "BS 7974 Application of Fire Safety Engineering Principles to the Design of Buildings-Code of Practice," British Standards Institute, London, UK, 2001.

[23] CIBSE Guide E, “Fire Engineering,” The Chartered Institution of Building Services Engineers, London, UK, 2010.

[24] J. H. Klote and J. Milke, "Design of smoke management systems," ASHRAE Publications 90022, 1992.

[25] "ASTM E-1546 Standard Guide for Development of FireHazard-Assessment Standards," American Society for Testing and Materials, Philadelphia, Pa, USA, 2000.

[26] B. Hume, "Development of standards for fire field models," Fire Research Report 85, Fire Research Division, Office of the Deputy Prime Minister, London, UK, November, 2003.

[27] W. K. Chow, "Review on fire models and their application to design based on 'fire engineering approach", in Proceedings of the International Conference on Building Fire Safety, pp. 12-24, Gardens Point Campus, Queensland University of Technology, Brisbane, Queensland, Australia, November 2003.

[28] W. K. Mok and W. K. Chow, "'Verification and validation' in modeling fire by computational fluid dynamics," International Journal on Architectural Science, vol. 5, no. 3, pp. 58-67, 2004.

[29] R. N. Mawhinney, E. R. Galea, N. Hoffmann, and M. K. Patel, "A critical comparison of a phoenics based fire field model with experimental compartment fire data," Journal of Fire Protection Engineering, vol. 6, no. 4, pp. 137-152, 1994.

[30] Z. Wang, F. Jia, E. R. Galea, M. K. Patel, and J. Ewer, "Simulating one of the CIB W14 round robin test cases using the SMARTFIRE fire field model," Fire Safety Journal, vol. 36, no. 7, pp. 661-677, 2001.

[31] W. L. Oberkampf and T. G. Trucano, "Verification and validation in computational fluid dynamics," SAND20020529, Sandia National Laboratories, Albuquerque, NM, USA, 2002.

[32] R. D. Peacock, W. W. Jones, and R. W. Bukowski, "Verification of a model of fire and smoke transport," Fire Safety Journal, vol. 21, no. 2, pp. 89-129, 1993.

[33] H. Ingasson and S. Olsson, "Interaction between sprinklers and fire vents," SP Report 1992.11, Swedish National Testing and Research Institute, Boras, Sweden, 1992.
[34] D. Steckler, J. G. Quintiere, and W. J. Rinkinen, "Flow induced by fire in a compartment," NBSIR 82-2520, U.S. National Bureau of Standards, 1982.

[35] J. Hietniemi, S. Hostikka, and J. Vaari, "FDS simulation of fire spread-comparison of model results with experimental data," ESPOO2004, VVT Working Papers 4, VVT Building and Transport, Espoo, Finland, 2004.

[36] "Verification and Validation of Selected Fire Models for Nuc lear Power Plant Applications (NUREG-1824, Vols. 1-7)," Draft Report for Comment, US Nuclear Regulatory Commission plans, http://www.nrc.gov/reading-rm/doc-collections/nuregs/staff/sr1824/.

[37] W. K. Chow, "Necessity of carrying out hot smoke tests and a case study," in Proceedings of the Workshop on the Trends of Fire Safety and Smoke Control in Building, pp. 1-19, National Taipei University of Science and Technology organized by Architectural and Building Research Institute, Ministry of Interior, Taipei, Taiwan, December 2005.

[38] W. K. Chow, "Atrium smoke exhaust and technical issues on hot smoke tests," in ASME Summer Heat Transfer Conference, pp. 1-4, San Francisco, Calif, USA, July 2005, Paper HT200572412.

[39] W. K. Chow, "Technical issues on atrium hot smoke tests," in Proceedings of the Fire Science and Engineering-the 2nd Conference on the Development of Performance-Based Fire Code, pp. 267-272, November 2005.

[40] W. K. Chow, "Atrium hot smoke tests in evaluating performance of smoke exhaust systems," in Proceedings of the International Congress "Smoke Control in Buildings and Tunnels", School of Industrial and Telecommunication Engineers, Santander, Spain, October 2008.

[41] W. K. Chow, S. S. Li, and C. L. Chow, "Justification of fire field models by atrium hot smoke tests," in ASME Summer Heat Transfer Conference (HT '09), pp. 21-25, San Francisco, Calif, USA, July 2009.

[42] E. E. Khalil, "Private communications at 10th AIAA/ASME Joint Thermophysics and Heat Transfer Conference," Chicago, Ill, USA, June-July 2010.

[43] G. W. Zou, H. P. Tan, W. K. Chow, and Y. Gao, "Effects of varying Smagorinsky constant on simulating post-flashover fires," International Journal of Computational Fluid Dynamics, vol. 21, no. 2, pp. 107-119, 2007.

[44] W. J. Minkowycz, E. M. Sparrow, G. E. Schneider, and R. H. Pletcher, Handbook of Numerical Heat Transfer, John Wiley \& Sons, New York, NY, USA, 1988.

[45] W. K. Chow and Y. L. Cheung, "Selection of differencing schemes on simulating the sprinkler hot-air layer problem," Numerical Heat Transfer Part A, vol. 35, no. 3, pp. 311-330, 1999.

[46] W. Q. Tao, Y. L. He, Z. Y. Li, and Z. G. Qu, "Some recent advances in finite volume approach and their applications in the study of heat transfer enhancement," International Journal of Thermal Sciences, vol. 44, no. 7, pp. 623-643, 2005.

[47] R. I. Issa, "Solution of the implicitly discretised fluid flow equations by operator-splitting," Journal of Computational Physics, vol. 62, no. 1, pp. 40-65, 1986.

[48] K. B. McGrattan, H. R. Baum, R. G. Rehm et al., "Fire dynamics simulator (version 4)-technical reference guide," NIST Special Publication 1018, US Department of Commerce, National Institute of Standards and Technology, July 2004.

[49] K. B. McGrattan, G. P. Forney, J. E. Floyd, S. Hostikka, and K. Prasad, "Fire dynamics simulator (version 4)—user's guide," NIST Special Publication 1019, US Department of Commerce, National Institute of Standards and Technology, July 2004. 
[50] S. J. Emmerich and K. B. McGrattan, "Application of a large eddy simulation model to study room airflow," in Proceedings of the ASHRAE Winter Meeting, pp. 1128-1140, San Francisco, Calif, USA, January 1998.

[51] W. Zhang, A. Hamer, M. Klassen, D. Carpenter, and R. Roby, "Turbulence statistics in a fire room model by large eddy simulation," Fire Safety Journal, vol. 37, no. 8, pp. 721-752, 2002.

[52] American Institute of Aeronautics and Astronautics, "Guide for the verification and validation of computational fluid dynamics simulations," in American Institute of Aeronautics and Astronautics, Reston, Va, USA, 1998, AIAA G-077-1998.

[53] P. J. Roache, Verification and Validation in Computational Science and Engineering, Hermosa, Albuquerque, NM, USA, 1998.

[54] G. W. Zou and W. K. Chow, "Evaluation of the field model, fire dynamics simulator, for a specific experimental scenario," Journal of Fire Protection Engineering, vol. 15, no. 2, pp. 77-92, 2005.

[55] R. D. Peacock, P. A. Reneke, W. D. Davis W., and W. W. Jones, "Quantifying fire model evaluation using functional analysis," Fire Safety Journal, vol. 33, no. 3, pp. 167-184, 1999.

[56] G. P. Forney and W. F. Moss, "Analyzing and exploiting numerical characteristics of zone fire models," Fire Science and Technology, vol. 14, no. 1, pp. 49-60, 1994.

[57] W. K. Chow and G. W. Zou, "Numerical simulation of pressure changes in closed chamber fires," Building and Environment, vol. 44, no. 6, pp. 1261-1275, 2009.

[58] B. Hägglund, K. Nireus, and P. Werling, Effects of Inlets on Natural Fire Vents: An Experimental Study, National Defence Research Establishment Department of Weapons and Protection, Stockholm, Sweden, 1996.

[59] S. S. Li and W. K. Chow, "Application of computational fluid dynamics in simulating fire-induced air flow in large halls," in Proceedings of the 8th Asia-Oceania Symposium on Fire Science and Technology, Melbourne, Australia, December 2010.

[60] A. Schaelin, J. van der Maas, and A. Moser, "Simulation of airflow through large openings in buildings," in Proceedings of the ASHRAE Winter Meeting, pp. 319-328, Anaheim, Calif, USA, January 1992.

[61] S. S. Li and W. K. Chow, "Validation of fire models predictions with a room fire test," in Proceedings of the Annual Meeting SFPE Professional Development Conference and Exposition, Scottsdale, Ariz, USA, October 2009.

[62] W. K. Chow, "A brief on performance-based design for building fire safety," in Proceedings of the International Conference on Safety \& Security Management and Engineering Technology (ICSSMET '09), Chiayi, Taiwan, December 2009.

[63] S. M. Lo and R. K. K. Yuen, "Views of building professionals in the implementation aspects of fire safety engineering approach in building design: a preliminary study," International Journal on Engineering Performance-Based Fire Codes, vol. 1, no. 3, pp. 129-133, 1999.

[64] J. A. Milke, "Education issues," in Proceedings of the 2nd Conference on Fire Safety Design in the 21st Century, pp. 179184, Worcester Polytechnic Institute, Worcester, Mass, USA, June 1999. 

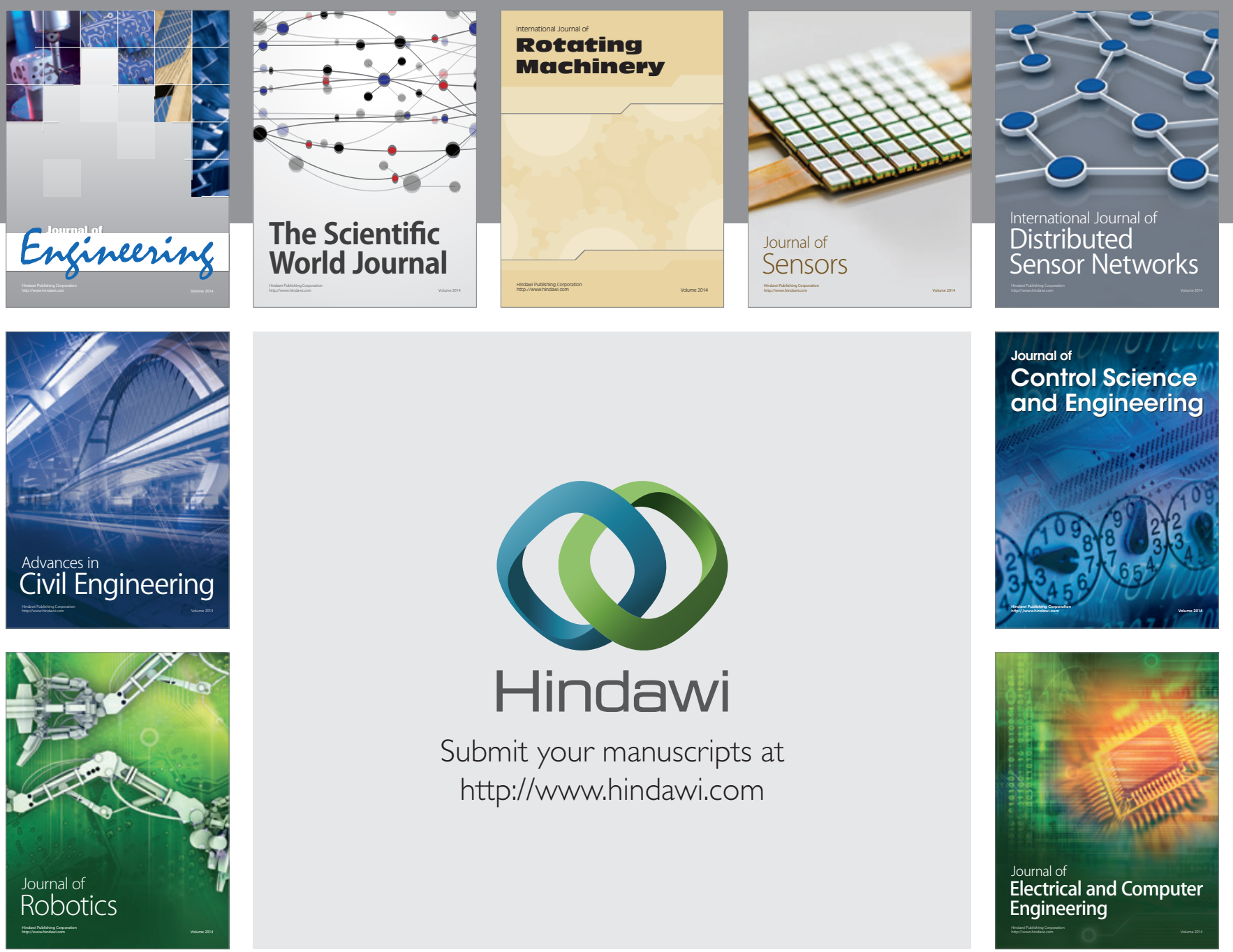

Submit your manuscripts at

http://www.hindawi.com
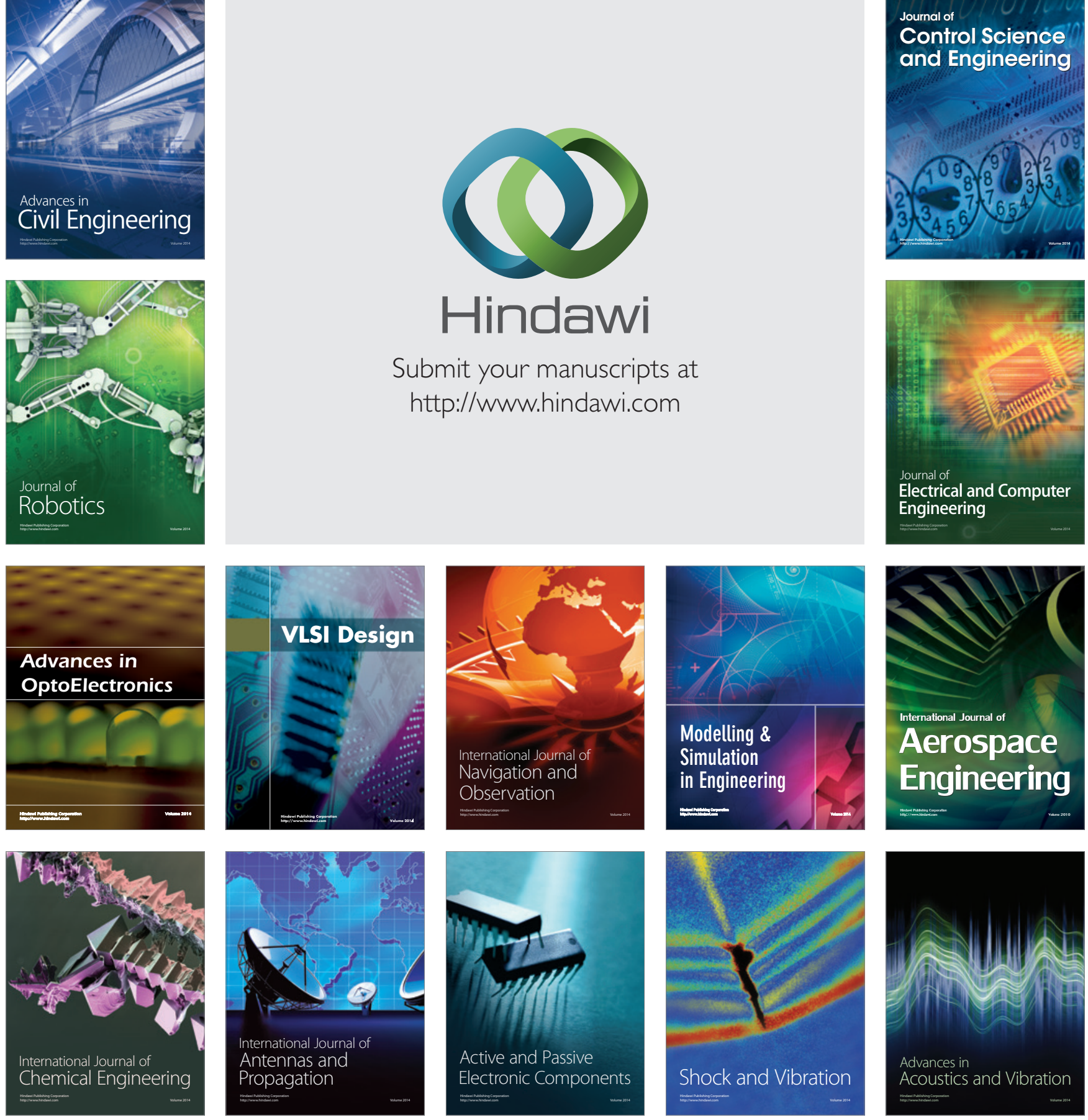